\title{
Measurement and modeling of neutral, radical, and ion densities in $\mathbf{H}_{2}-\mathbf{N}_{2}$-Ar plasmas
}

M. Sode, ${ }^{1, \text { a) }}$ W. Jacob, ${ }^{1}$ T. Schwarz-Selinger, ${ }^{1}$ and H. Kersten ${ }^{2}$

1) Max-Planck-Institut für Plasmaphysik, Boltzmannstraße 2, D-85748 Garching,

Germany.

${ }^{2)}$ Institute for Experimental and Applied Physics, ChristianAlbrechts-Universität zu Kiel, Leibnizstraße 11-19, D-24098 Kiel, Germany.

(Dated: 28 February 2015)

A comprehensive experimental investigation of absolute ion and neutral species densities in an inductively coupled $\mathrm{H}_{2}-\mathrm{N}_{2}$-Ar plasma was carried out. Additionally, the radical and ion densities were calculated using a zero-dimensional rate equation model. The $\mathrm{H}_{2}-\mathrm{N}_{2}$-Ar plasma was studied at a pressure of $1.5 \mathrm{~Pa}$ and an $r f$ power of $200 \mathrm{~W}$. The $\mathrm{N}_{2}$ partial pressure fraction was varied between $f_{\mathrm{N}_{2}}=0 \%$ and $56 \%$ by a simultaneous reduction of the $\mathrm{H}_{2}$ partial pressure fraction. The Ar partial pressure fraction was held constant at about $1 \% \cdot \mathrm{NH}_{3}$ was found to be produced almost exclusively on the surfaces of the chamber wall. $\mathrm{NH}_{3}$ contributes up to $12 \%$ to the background gas.

To calculate the radical densities with the rate equation model it is necessary to know the corresponding wall loss times $t_{\text {wrad }}$ of the radicals. $t_{\text {wrad }}$ was determined by the temporal decay of radical densities in the afterglow with ionization threshold mass spectrometry during pulsed operation and based on these experimental data the absolute densities of the radical species were calculated and compared to measurement results.

Ion densities were determined using a plasma monitor (mass and energy resolved mass spectrometer). $\mathrm{H}_{3}^{+}$is the dominant ion in the range of $0.0 \leq f_{\mathrm{N}_{2}}<3.4 \%$. For $3.4<f_{\mathrm{N}_{2}}<40 \% \mathrm{NH}_{3}^{+}$and $\mathrm{NH}_{4}^{+}$are the most abundant ions and agree with each other within the experimental uncertainty. For $f_{\mathrm{N}_{2}}=56 \% \mathrm{~N}_{2} \mathrm{H}^{+}$is the dominant ion while $\mathrm{NH}_{3}^{+}$and $\mathrm{NH}_{4}^{+}$have only a slightly lower density. Ion species with densities in the range between 0.5 and $10 \%$ of $n_{i, t o t}$ are $\mathrm{H}_{2}^{+}, \mathrm{ArH}^{+}$, and $\mathrm{NH}_{2}^{+}$. Ion species with densities less than $0.5 \%$ of $n_{i, t o t}$ are $\mathrm{H}^{+}, \mathrm{Ar}^{+}, \mathrm{N}^{+}$, and $\mathrm{NH}^{+}$. Our model describes the measured ion densities of the $\mathrm{H}_{2}-\mathrm{N}_{2}$-Ar plasma reasonably well. The ion chemistry, i.e., the production and loss processes of the ions and radicals, are discussed in detail. The main features, i.e., the qualitative abundance of the ion species and the ion density dependence on the $\mathrm{N}_{2}$ partial pressure fraction, are well reproduced by the model.

PACS numbers: 52.25.-b, 52.27.Cm, 52.20.Hv, 52.70.Nc

Keywords: radical wall loss time, ion densities, rate equation model, ammonia

a)Electronic mail: maik.sode@ipp.mpg.de 


\section{INTRODUCTION}

Plasmas containing $\mathrm{H}_{2}-\mathrm{N}_{2}$ are extensively applied for thin film growth and material processing on the nanometer scale ${ }^{1-3}$. For example, thin films of silicon nitride which are fabricated by plasma-enhanced chemical vapor deposition (PECVD) in the semiconductor industry are used as passivation layers ${ }^{4}$ and in the photovoltaic industry ${ }^{3,5}$. For the etching of organic low-k layers hydrofluorocarbons are replaced by $\mathrm{H}_{2}-\mathrm{N}_{2}$ due to economic and ecological reasons ${ }^{6,7}$. Other applications of $\mathrm{H}_{2}-\mathrm{N}_{2}$ plasmas are nitriding 8,9 , the plasma-enhanced atomic layer deposition of $\mathrm{TaN}$ and $\mathrm{TiN}$ thin films ${ }^{8,10}$, the etching of organic low dielectric constant (low-k) films ${ }^{6,8,11}$ and the chemical synthesis of ammonia ${ }^{8,12,13}$. The latter is also of interest in nuclear fusion research where $\mathrm{N}_{2}$ is puffed into the plasma edge of the hydrogen plasma to reduce the local heat load of the so-called divertor region ${ }^{14-19}$. Argon addition to $\mathrm{H}_{2}-\mathrm{N}_{2}$ plasmas is applied in fusion plasmas ${ }^{16,17}$ as well as for industrial nitriding treatments of ferrous and nonferrous materials for improving the mechanical properties or corrosion resistance ${ }^{20,21}$. In many of these plasmas the dominant plasma-surface-interaction processes are driven by radical species or ions or a synergistic interaction, respectively, between them. Hence, a quantitative determination of ion and radical densities is a prerequisite for an improved understanding of plasma-surface-interactions in those reactive plasmas.

In two preceding publications ${ }^{22,23}$ a comprehensive investigation of a $\mathrm{H}_{2}$-Ar plasma was presented. The densities of the gas species, the radical species $\mathrm{H}$, the electrons and the ion species as well as the temperature of the gas were determined experimentally ${ }^{22}$. Furthermore, by a rate equation model the ion densities, the atomic hydrogen density and the electron temperature were studied theoretically ${ }^{23}$. One of the main result of Refs. ${ }^{22,23}$, namely the ion species distribution, is in reasonable agreement with recent publications of Fox-Lyon et al. ${ }^{24}$ and Jimenez-Redondo et al. ${ }^{25}$ studying $\mathrm{H}_{2}$-Ar plasmas at comparable pressures. $\mathrm{The}_{2}-\mathrm{Ar}$ plasma can be considered as a model system with a much lower complex plasma chemistry than a $\mathrm{H}_{2}-\mathrm{N}_{2}$-Ar plasma. For this model system the experimental methods as well as the rate equation model were benchmarked for our experimental setup and will here be applied for the more complex $\mathrm{H}_{2}-\mathrm{N}_{2}$-Ar plasma.

In low temperature $\mathrm{H}_{2}-\mathrm{N}_{2}$-Ar plasmas $\mathrm{H}_{2}, \mathrm{~N}_{2}$, Ar, and $\mathrm{NH}_{3}-\mathrm{NH}_{3}$ is produced in the plasma - are the stable background gas species. $\mathrm{H}, \mathrm{N}, \mathrm{NH}$, and $\mathrm{NH}_{2}$ are the relevant radical species. The primary ions which are produced by electron-induced ionization of neutrals are $\mathrm{H}_{2}^{+}, \mathrm{N}_{2}^{+}, \mathrm{Ar}^{+}$, and $\mathrm{NH}_{3}^{+}$as well as $\mathrm{H}^{+}, \mathrm{N}^{+}, \mathrm{NH}^{+}$, and $\mathrm{NH}_{2}^{+}$. In addition, the secondary ions $\mathrm{H}_{3}^{+}, \mathrm{NH}_{4}^{+}, \mathrm{N}_{2} \mathrm{H}^{+}$, and $\mathrm{ArH}^{+}$, which are solely produced by ion-molecule reactions, appear. Furthermore, $\mathrm{N}_{2} \mathrm{H}_{x}$ neutrals and their ions can also appear (see, e.g., Ref. ${ }^{26}$ ), but due to their extremely low density these species are not considered in the present work.

A similar extensive study of $\mathrm{H}_{2}-\mathrm{N}_{2}$ plasmas as in the present work was carried out by Carrasco et al..$^{3,27,28}$ in a DC hollow cathode discharge with comparable plasma conditions. Carrasco et al. presented experimental and modeling results for densities of ionic, electron, radical and gas species. The basic mechanisms leading to the observed neutral and ion distributions, as well as their relative importance in the studied pressure range, were identified and discussed. Jang and Lee ${ }^{29}$ previously examined a few aspects in an inductively coupled $\mathrm{H}_{2}-\mathrm{N}_{2}$ plasma by measuring $n_{e}, T_{e}$ and ion signal intensities. In addition, there 
exists a variety of studies about $\mathrm{H}_{2}-\mathrm{N}_{2}$ plasmas in which the densities of background gas species $^{13,20,30-33}$, radicals $^{7,8,20,32,34}$, electrons $^{34,35}$ and ion signals ${ }^{7,36}$ as well as the surface loss probability of $\mathrm{H}$ and $\mathrm{N}$ (see Ref. ${ }^{7}$ ) were reported. Other studies have calculated the most important species densities using rate equation models ${ }^{37-40}$. However, these studies rarely compared calculated results with experimental data. Therefore, an assessment of rate equation models with experimental data is only partially given. Argon admixtures to hydrogen and nitrogen containing plasmas were examined in the studies of Refs. ${ }^{20,26,31,35,36}$.

In $\mathrm{H}_{2}-\mathrm{N}_{2}$ plasmas $\mathrm{NH}_{3}$ is commonly produced by plasma chemical reactions. The formation of $\mathrm{NH}_{3}$ is quantitatively not yet fully understood, but it is generally assumed that $\mathrm{NH}_{3}$ is produced mainly by surface reactions at the plasma surrounding wall ${ }^{3,30,38}$. Atomic nitrogen and hydrogen originating from electron-impact dissociation in the plasma are expected to synthesize on the surface resulting in $\mathrm{NH}_{x}(x=1,2)$ and finally in $\mathrm{NH}_{3}$. Surface reaction models describing the production of $\mathrm{NH}_{3}$ are available from Gordiets et al. ${ }^{37,38}$ and Carrasco et al. ${ }^{3,28}$.

In the present work a comprehensive investigation of an inductively coupled $\mathrm{H}_{2}-\mathrm{N}_{2}-\mathrm{Ar}$ plasma at $1.5 \mathrm{~Pa}$ is performed. The total pressure of $1.5 \mathrm{~Pa}$ is kept constant while the $\mathrm{N}_{2}$ partial pressure fraction $f_{\mathrm{N}_{2}}$ is varied between $0 \%$ and $56 \%$ whereas the $\mathrm{H}_{2}$ partial pressure fraction $f_{\mathrm{H}_{2}}$ is reduced correspondingly. The Ar partial pressure fraction is fixed at $1 \%$. Densities $n_{j}$ of background gas species, wall loss times $t_{w r a d}$ and densities $n_{\text {rad }}$ of radicals, the gas temperature $T_{g}$, the electron temperature $T_{e}$, the electron density $n_{e}$, and ion densities $n_{i}$ will be presented. The same measurement methods and rate equation model as in a preceding study of a $\mathrm{H}_{2}$-Ar plasma ${ }^{22,23}$ are applied here. The determined ion densities will be discussed and compared with the model results. Finally the ion chemistry, i.e., the dominant plasma-chemical reactions in the plasma, will be specified based on the model results.

\section{EXPERIMENT}

\section{A. Plasma chamber setup}

In the following we briefly present the experimental methods. A detailed description can be found in Ref. ${ }^{22}$. The experimental setup consists of a cylindrical stainless steel plasma chamber. The discharge is generated by a planar coil with 5 turns driven by a radio frequency $(r f)$ generator operating at $13.56 \mathrm{MHz}$ (Dressler Cesar 136). The coil is separated from vacuum by a quartz dome ${ }^{41}$. The top part of the dome acts as the dielectric window for the $r f$ power. The outer diameter $d_{e l}$ of the quartz window and the upper stainless steel electrode is $d_{e l}=2 r_{e l}=131 \mathrm{~mm}$ where $r_{e l}$ is the corresponding radius. The distance $l_{e l}$ between the stainless steel electrode and dielectric quartz window is $l_{e l}=60 \mathrm{~mm}$. The plasma is mainly generated in the assumed cylinder with the volume $V=\pi r_{e l}^{2} l_{e l}=0.80 \mathrm{l}$ between the electrode and the quartz window although at $r_{e l}$ there is no radial side wall between the stainless steel electrode and dielectric window. The stainless steel vacuum chamber has a radius of $r_{c h}=125 \mathrm{~mm}$ and a total height of $l_{c h}=360 \mathrm{~mm}$.

In this work $\mathrm{H}_{2}-\mathrm{N}_{2}$-Ar low-temperature plasmas with variable $\mathrm{N}_{2}$ content are investigated. 
The total pressure of $1.5 \mathrm{~Pa}$ is kept constant while the $\mathrm{N}_{2}$ partial pressure fraction $f_{\mathrm{N}_{2}}$ is increased on expense of $f_{\mathrm{H}_{2}}$. A constant $r f$ power of $200 \mathrm{~W}$ is used in all experiments. A butterfly valve in front of the turbo molecular pump allows to throttle the pumping speed. All experiments were conducted with a fixed butterfly position so that the residence time of the species was constant $\left(t_{\mathrm{H}_{2}}=0.19 \mathrm{~s}, t_{\mathrm{N}_{2}}=0.77 \mathrm{~s}, t_{\mathrm{Ar}}=31 \mathrm{~s}\right)$. The incoming gas flows were adjusted with mass-flow controllers. For the chosen butterfly position the required gas flows to achieve the working pressure of $1.5 \mathrm{~Pa}$ are $\Phi_{\max , \mathrm{H}_{2}}=79.5 \mathrm{sccm}$ in case of pure $\mathrm{H}_{2}$ and $\Phi_{\max , \mathrm{N}_{2}}=20 \mathrm{sccm}$ for pure $\mathrm{N}_{2}$. For different gas mixtures $\Phi_{\mathrm{N}_{2}}$ is increased from 0 to $20 \mathrm{sccm}$ whereas $\Phi_{\mathrm{H}_{2}}$ is lowered from 79.5 to $24 \mathrm{sccm}$. For all measurements a constant Ar gas flow of $\Phi_{\mathrm{Ar}}=0.5 \mathrm{sccm}$ is used. The working pressure prior to plasma ignition of $p=1.5 \mathrm{~Pa}$ is used for all considered plasma conditions shown here.

\section{B. Partial pressures}

Previous investigations by mass spectrometry have shown that for the applied experimental conditions the flux ratios of the working gases are not identical to the partial pressure fractions ${ }^{22}$. Therefore, the actual partial pressure fractions $f_{j}$ for a gas species $j$ used in the experiment were determined with a quadrupole mass spectrometer. A differentially pumped molecular-beam mass spectrometer 'MBMS' (QMG 422, Pfeiffer Vacuum) with cross-beam ion source was used to measure the actual partial pressures in the gas mixtures (see also Ref. ${ }^{22}$ for details). Particles are sampled through an capillary at the outer diameter of the vessel in the central plane. The partial pressure fraction is defined as $f_{j}=p_{j} / p_{\text {tot }}$ where $p_{j}$ and $p_{\text {tot }}$ are the partial and total pressures measured with the MBMS, respectively. The mass spectrometer chamber is equipped with a stainless steel shutter behind the capillary to allow distinguishing the isotropic background signal inside the chamber from the signal due to the molecular beam that is formed by the capillary. The particle density in this molecular beam is proportional to the particle density in the vessel ${ }^{42}$. Therefore, the beam signals are a good measure for the particle densities and accordingly partial pressures. The beam component was obtained by subtracting the signal with closed shutter from the signal with opened shutter. The beam-to-background ratio $R$ was measured and yields for $\mathrm{H}_{2}$ $R_{\mathrm{H}_{2}}=1.5 \pm 0.1$, for $\mathrm{N}_{2} R_{\mathrm{N}_{2}}=4.4 \pm 0.3$, for Ar $R_{\mathrm{Ar}}=5.0 \pm 0.3$, and for $\mathrm{NH}_{3} R_{\mathrm{NH}_{3}}=3.8 \pm 0.3$. The values are independent on pressure in the considered range up to $1.5 \mathrm{~Pa}$.

In the following the procedure for determining the partial pressure fraction is described. A certain flow of a pure gas corresponds to a certain pressure in the main chamber for the fixed butterfly position. This pressure corresponds to the beam component measured with the mass spectrometer. The beam components of the mass spectrometer signals for the pure gases were calibrated against the pressure in the main chamber measured with a capacitive manometer. This calibration was made for the full partial pressure range applied in the experiments. The such calibrated mass spectrometer was in the following used to measure the partial pressures of the gas species in the gas mixtures. 


\section{Gas temperature and actinometry}

Optical emission spectroscopy (OES) was applied to measure the gas temperature and the dissociation degree of hydrogen as described in Ref. ${ }^{22}$. The used spectrometer is a Czerny-Turner spectrograph (Acton SpectraPro 275) with a focal length of $275 \mathrm{~mm}$. The experiments were conducted with a 1800 lines/mm grating, which has a resolution of $0.15 \mathrm{~nm}$ at $\lambda=600 \mathrm{~nm}$.

The $\mathrm{H}_{2}$ gas temperature $T_{g}$ is derived from the rotational temperature $T_{\text {rot }}$ of the $\mathrm{H}_{2}$ molecule. $T_{\text {rot }}$ of the hydrogen molecule is derived from the rotational lines $Q_{1}-Q_{3}$ of the Q-branch of the $\mathrm{H}_{2}$ Fulcher- $\alpha$ diagonal band $\left(v^{6}=v^{*}=2\right)$ with experimental uncertainty of $50 \mathrm{~K}^{22}$. $T_{\text {rot }}$ was experimentally determined for all considered $\mathrm{N}_{2}$ partial pressures. A mean value of $T_{\text {rot }}=460 \pm 50 \mathrm{~K}$ is obtained. We want to note that in a former study ${ }^{43}$ the rotational temperature of molecular nitrogen was evaluated from the spectrum of the transition $v^{6}=0 \rightarrow v^{\prime \prime}=2$ of the second positive system $\left(C^{3} \Pi_{u} \rightarrow B^{3} \Pi_{g}\right)$ of $\mathrm{N}_{2}$. $T_{\text {rot }}$ from $\mathrm{H}_{2}$ and $\mathrm{N}_{2}$ were in very good agreement with each other within the experimental uncertainty (see Ref. ${ }^{43}$ ). $T_{\text {rot }}$ is, therefore, taken as an estimate of the gas temperature $T_{g}$ and is applied to calculate the gas densities according to an ideal gas law:

$$
n_{j}=f_{j} \frac{p}{k_{B} T_{g}}
$$

for the background gas $j$ with the partial pressure fraction $f_{j}\left(k_{B}\right.$ - Boltzmann constant).

The dissociation degree of hydrogen is here defined as $n_{\mathrm{H}} / n_{\mathrm{H}_{2}}$ with $n_{\mathrm{H}}$ being the atomic hydrogen density and $n_{\mathrm{H}_{2}}$ the molecular hydrogen density in the plasma. $n_{\mathrm{H}} / n_{\mathrm{H}_{2}}$ was determined by actinometry using the ratio of the $\mathrm{H}_{\beta} / \mathrm{Ar}_{750}$ lines as described in Ref. ${ }^{44}$. The experimental uncertainty for the dissociation degree is $24 \%$ (see Ref. $^{44}$ ).

\section{Electron temperature and density}

The electron energy distribution function (EEDF), the electron temperature $T_{e}$, and the electron density $n_{e}$ were determined by a single-tip Langmuir probe system ${ }^{22}$. The probe consists of a single cylindrical tungsten tip $4 \mathrm{~mm}$ in length and $40 \mu \mathrm{m}$ in diameter. I-V curves are acquired with the control and measuring unit PlasmaMeter ${ }^{45,46} . T_{e}$ is calculated by the potential difference $\Delta V=V_{p l}-V_{f l} \operatorname{method}^{22}$, where $V_{p l}$ and $V_{f l}$ denote the plasma and the floating potential, respectively, and $n_{e}$ is calculated by integrating the EEDF ${ }^{22}$. The Langmuir probe measurements were performed in the axial center of the plasma $(r=0 \mathrm{~mm})$, $20 \mathrm{~mm}$ above the quartz window.

\section{E. Ion densities}

A combined energy and mass analyzer (Pfeiffer plasma process monitor PPM 422, Inficon AG Balzers) - in the following designated as plasma monitor (PM) - is incorporated into the upper, grounded electrode. The plasma monitor is twofold differentially pumped resulting 
in a background pressure of the order of $10^{-6} \mathrm{~Pa}$ for a working pressure of $1 \mathrm{~Pa}$ in the plasma chamber. Particles are sampled through two aligned orifices (100 and $500 \mu \mathrm{m}$ in diameter, respectively) at the center of the electrode. The plasma monitor consists of an einzel lens (EL), an electron-impact ionizer (IZ) to detect neutrals, a cylindrical-mirror energy analyzer (CMA), a quadrupole mass filter (QMS), and a secondary electron multiplier (SEM) as particle detector arranged in series. There is also a Faraday cup as particle detector installed, but because of better dynamic range the SEM was used in this study. A discriminator voltage $V_{\mathrm{PM}}$ accelerates or decelerates incoming ions to a constant pass energy of $15 \mathrm{eV}$ in the energy filter. The plasma monitor measures either in the so called "mass mode" at a fixed discriminator voltage $V_{\mathrm{PM}}$ or in the so called "energy mode" at a fixed mass to charge ratio $M_{i}$ of a species $i$ (here only singly charged ions are assumed).

A calibration procedure was applied to derive absolute ion densities from mass-resolved signal intensities of the $\mathrm{PM}^{22}$. The calibration procedure considers the energy-dependent $\left(T_{e d}\right)$ and mass-dependent $\left(T_{m d}\right)$ transmission of the plasma monitor. In our case the ion energy distributions (IED) for one plasma condition are similar in position and shape. In first order approximation only the heights $H_{\mathrm{PM}, i}$ of the IEDs vary with individual ion species $i$. As it was shown in Ref. ${ }^{22}$ it is possible to convert $H_{\mathrm{PM}, i}$ into relative ion fluxes $j_{\mathrm{PM}, i, r e l}$ :

$$
j_{\mathrm{PM}, i, r e l} \propto 1 / T_{m d}\left(M_{i}\right) \times H_{\mathrm{PM}, i}
$$

$\left(M_{i}\right.$ - mass of ion species $\left.i\right)$. In Ref. ${ }^{22}$ a Faraday cup was used as detector and, therefore, $T_{m d}$ was only determined by the quadrupole. Here we have to take into account also the massdependent sensitivity of the SEM. However, analyzing the mass-dependent transmission of the SEM has shown, that $T_{m d}$ agrees between SEM and Faraday cup except for the light ions $i=\mathrm{H}^{+}, \mathrm{H}_{2}^{+}, \mathrm{H}_{3}^{+}$. Furthermore, for these light ions the shapes, i.e., the energy of the maximum of the ion energy distribution, differ slightly from those of the other ion species. Therefore, for $i=\mathrm{H}^{+}, \mathrm{H}_{2}^{+}, \mathrm{H}_{3}^{+}$correction factors are determined accounting for the deviation in the maxima of the ion energy distributions and the difference between measurements with SEM and Faraday cup.

The conversion from relative fluxes into relative ion densities $n_{\mathrm{PM}, i, r e l}$ is based on a sheath and density profile model ${ }^{22}$ :

$$
n_{\mathrm{PM}, i, r e l}=\sqrt{M_{i}} / h_{l, i} \times j_{\mathrm{PM}, i, r e l} .
$$

where $h_{l, i}$ is the ion density ratio between sheath edge and plasma bulk (see Sec. III C). To convert these relative fluxes to absolute fluxes the electron density $n_{e}$ measured with the Langmuir probe is used. The calibration factor $C_{c a l i b}$ which converts relative ion densities into absolute ion densities is obtained from

$$
C_{\text {calib }}=\frac{n_{e}}{\sum_{i} n_{\mathrm{PM}, i, r e l}} .
$$

$n_{e}$ is set equal to the total ion density due to quasi neutrality.

The reproducibility of the plasma monitor was checked by repeating the whole set of $\mathrm{H}_{2}-\mathrm{N}_{2}$-Ar measurements with the same experimental settings on two different days. The 
standard deviation of the relative changes of the individual plasma monitor signal heights determined from this comparison was $15 \%$.

\section{F. Radical wall loss times}

The radical wall loss time which is an important model input parameter is determined by monitoring the radical density in the temporal afterglow of the plasma with ionization threshold mass spectroscopy (ITMS) ${ }^{47-53}$. This technique takes advantage of the fact that the threshold energy for direct ionization of a radical, e.g., $e^{-}+\mathrm{N} \rightarrow \mathrm{N}^{+}+2 e^{-}$is lower than the threshold energy for the corresponding dissociative ionization of the mother molecules leading to the same ion, e.g., $e^{-}+\mathrm{N}_{2} \rightarrow \mathrm{N}^{+}+\mathrm{N}+2 e^{-}$. The electron energy $E_{\text {cath }}$ in the ionizer is set between these two thresholds. This allows discriminating the radical signal from the signal of stable neutrals which are usually much more abundant. The experimental technique applied here is described in detail in Ref. ${ }^{43}$. For the measurement of relative radical densities the plasma monitor in the neutral modus is used operating with a fixed electron energy $E_{\text {cath }}$. For atomic nitrogen (mass channel $14 \mathrm{amu} / \mathrm{e}$ ) a $E_{\text {cath }}$ of $18 \mathrm{eV}$ is used. The determination of the used $E_{\text {cath }}$ for $\mathrm{N}$ is explained in detail in Ref. ${ }^{43}$. For the radicals hydrogen $\mathrm{H}$ on mass channel $1 \mathrm{amu} / \mathrm{e}$ (deuterium $\mathrm{D}$ on $2 \mathrm{amu} / \mathrm{e}$ ), $\mathrm{NH}$ on mass channel $15 \mathrm{amu} / \mathrm{e}$ (ND on $16 \mathrm{amu} / \mathrm{e}$ ), and $\mathrm{NH}_{2}$ on mass channel $16 \mathrm{amu} / \mathrm{e}\left(\mathrm{ND}_{2}\right.$ on $\left.18 \mathrm{amu} / \mathrm{e}\right)$, the electron energies $E_{\text {cath }}\left(\mathrm{H}^{+}\right)=15 \mathrm{eV}, E_{\text {cath }}\left(\mathrm{NH}^{+}\right)=16 \mathrm{eV}$, and $E_{\text {cath }}\left(\mathrm{NH}_{2}^{+}\right)=14 \mathrm{eV}$ are used, respectively ${ }^{54}$.

For radicals the density in the afterglow and, hence, the signal intensity collected during one single decay is low. To increase counting statistics the plasma is operated in pulsed mode and signals are collected with a multi-channel scaler card. The signal pulses (measuring events) of the secondary electron multiplier of our mass spectrometer are detected by multichannel scaler cards (MCS, 65536 channels, Ortec). The pulsed plasma is operated with a power-on phase $\left(P_{o n}\right)$ with a duration of $t_{o n}$ and a power-off phase $\left(P_{o f f}\right)$ with a duration of $t_{\text {off }}$. A pulse generator is used which switches on and off the $r f$ generator and provides the trigger signal for the mass spectrometer measurements. For further details see Ref. ${ }^{43}$. The signal $S$ is computed from $S=N /\left(m_{\text {cycle }} \times t_{\text {dwell }}\right)\left(N\right.$ - counting events, $m_{\text {cycle }}$ - number of pulses, $t_{d w e l l}=0.05 \mathrm{~ms}$ - dwell time for $N$ ) and has the unit counts per second (cps).

\section{MODEL}

We apply a zero-dimensional rate equation model to calculate the ion densities $n_{i}$, the radical densities $n_{\text {rad }}$, and the electron temperature $T_{e}$ in these $\mathrm{H}_{2}-\mathrm{N}_{2}$-Ar plasmas. The model is described in detail in Ref. ${ }^{23}$ where it was applied to $\mathrm{H}_{2}$-Ar plasmas. The model takes into account densities of electrons, positive ions, radicals, and the stable background gas species. Furthermore, for $\mathrm{Ar}, \mathrm{N}_{2}$, and $\mathrm{N}$ excited levels are included. An overview of the considered species in the $\mathrm{H}_{2}-\mathrm{N}_{2}$-Ar plasma is given in Table I. For the particle balance, collisions in the volume and losses to the plasma-surrounding walls are taken into account.

The main input parameters for the model are all the required collision rate coefficients. 


\begin{tabular}{|c|c|}
\hline $\begin{array}{c}\text { background gas } \\
\text { radicals } \\
\text { electrons } \\
\text { ions }\end{array}$ & $\mathrm{H}, \mathrm{N}_{2}, \mathrm{Ar}, \mathrm{NH}_{3}$ \\
& $\mathrm{H}, \mathrm{NH}, \mathrm{NH}_{2}$ \\
excited species & $\mathrm{e}^{-}$ \\
& $\mathrm{H}^{+}, \mathrm{H}_{2}^{+}, \mathrm{H}_{3}^{+}, \mathrm{N}^{+}, \mathrm{NH}^{+}, \mathrm{NH}_{2}^{+}$, \\
& $\mathrm{NH}_{3}^{+}, \mathrm{NH}_{4}^{+}, \mathrm{N}_{2}^{+}, \mathrm{N}_{2} \mathrm{H}^{+}, \mathrm{Ar}^{+}, \mathrm{ArH}^{+}$ \\
$\mathrm{N}_{2}(A), \mathrm{N}_{2}(B), \mathrm{N}_{2}(C), \mathrm{N}_{2}\left(a^{\prime}\right)$, \\
$\mathrm{N}(D), \mathrm{N}(P), \operatorname{Ar}_{\text {meta }}, \operatorname{Ar}_{r}, \operatorname{Ar}(2 p)$ \\
\hline
\end{tabular}

TABLE I. Overview of the considered species in the $\mathrm{H}_{2}-\mathrm{N}_{2}$-Ar plasmas.

The remaining input parameters are experimentally obtained quantities, namely the electron density $n_{e}$, the gas temperature $T_{g}$, the total pressure $p$, the radical wall loss times, the partial pressure fractions $f_{j}$, and the geometry of the discharge vessel. The model output values are $n_{i}, n_{\text {rad }}$, and $T_{e}$. The densities are obtained by solving the rate equation system using the online available solver "Kinetic PreProcessor" ${ }^{55,56}$ (KPP). In KPP the rate equation system is solved using the Rosenbrock algorithm which is based on semi-implicit RungeKutta methods with adaptive stepsize. To achieve self-consistency the quasi-neutrality has to be fullfilled which is imposed externally as an additional boundary condition. The calculated electron temperature $T_{e}^{c}$ is varied to achieve the quasi-neutrality $n_{e}=\sum_{i} n_{i}$ where $i$ is the ion species. $T_{e}^{c}$ is accepted if the condition $0.98 \leq\left(\sum_{i} n_{i}\right) / n_{e} \leq 1.02$ is satisfied.

\section{A. Model assumptions}

The model is based on the following assumptions and simplifications:

1. The model is zero-dimensional.

2. The loss of particles to the surrounding walls is volume averaged. The model predicts species densities in the plasma center.

3. The calculated densities are determined for the steady state.

4. The temperature of the neutrals and ion species is described by one gas temperature $T_{g}$ which is set equal to the measured rotational temperature $T_{\text {rot }}$ of the $\mathrm{H}_{2}$ molecules $\left(T_{\text {rot }}=460 \mathrm{~K}\right.$, see Sec. II C).

5. The following reaction types are taken into account: electron collisions with the background gas, heavy-particle (i.e. ions) collisions with the background gas (see Sect. III B).

6. Wall loss for radicals (see Sect. IV) and for ions (see Sect. III C) is taken into account.

7. The following reaction types occurring in the plasma volume are not considered due to very low reaction rates: neutral heavy-particle collisions involving radicals, three-body interactions, and electron-ion recombination.

8. The following excited species are taken into account: excited levels of $\mathrm{Ar}, \mathrm{N}_{2}$, and $\mathrm{N}$ (see Sect. III D).

9. The following species are not taken into account: negative ions (due to very low concentrations with respect to the electron density ${ }^{37,57}$ ) and vibrationally excited molecular levels. 10. The density of $\mathrm{NH}_{3}$ is a model input parameter and is taken from the measurement. In this work no surface model for the description of the surface processes yielding $\mathrm{NH}_{3}$ is 


\begin{tabular}{|c|c|c|}
\hline$k$ & Reaction & $K\left(\mathrm{~m}^{3} \mathrm{~s}^{-1}\right)$ \\
\hline 1.1 & $\mathrm{e}^{-}+\mathrm{H}_{2} \rightarrow 2 \mathrm{H}+\mathrm{e}^{-}$ & $8.4 \times 10^{-14} T_{e}^{-0.45} \times e^{-11.18 / T_{e}} \sigma$ from $^{58}$ \\
\hline 1.2 & $\mathrm{e}^{-}+\mathrm{H} \rightarrow \mathrm{H}^{+}+2 \mathrm{e}^{-}$ & $1.1 \times 10^{-14} T_{e}^{0.29} \times e^{-15.28 / T_{e}} \sigma$ from $^{59}$ \\
\hline 1.3 & $\mathrm{e}^{-}+\mathrm{H}_{2} \rightarrow \mathrm{H}_{2}^{+}+2 \mathrm{e}^{-}$ & $2.3 \times 10^{-14} T_{e}^{0.19} \times e^{-17.87 / T_{e}} \sigma$ from $^{58}$ \\
\hline 1.4 & $\mathrm{e}^{-}+\mathrm{H}_{2} \rightarrow \mathrm{H}^{+}+\mathrm{H}+2 \mathrm{e}^{-}$ & $9.4 \times 10^{-16} T_{e}^{0.45} \times e^{-29.94 / T_{e}} \sigma$ from $^{58}$ \\
\hline 1.5 & $\mathrm{e}^{-}+\mathrm{Ar} \rightarrow \mathrm{Ar}^{+}+2 \mathrm{e}^{-}$ & $3.7 \times 10^{-14} T_{e}^{0.38} \times e^{-17.64 / T_{e}} \sigma$ from $^{60}$ \\
\hline 1.6 & $\mathrm{e}^{-}+\mathrm{N}_{2} \rightarrow \mathrm{N}+\mathrm{N}(D)+\mathrm{e}^{-}$ & $2.4 \times 10^{-14} T_{e}^{0.27} \times e^{-15.53 / T_{e}} \sigma$ from $^{61}$ \\
\hline 1.7 & $\mathrm{e}^{-}+\mathrm{N} \rightarrow \mathrm{N}^{+}+2 \mathrm{e}^{-}$ & $9.3 \times 10^{-15} T_{e}^{0.56} \times e^{-16.66 / T_{e}} \sigma$ from $^{62}$ \\
\hline 1.8 & $\mathrm{e}^{-}+\mathrm{N}_{2} \rightarrow \mathrm{N}_{2}^{+}+2 \mathrm{e}^{-}$ & $1.3 \times 10^{-14} T_{e}^{0.56} \times e^{-17.07 / T_{e}} \sigma$ from $^{61}$ \\
\hline 1.9 & $\mathrm{e}^{-}+\mathrm{N}_{2} \rightarrow \mathrm{N}^{+}+\mathrm{N}+2 \mathrm{e}^{-}$ & $2.9 \times 10^{-15} T_{e}^{0.72} \times e^{-29.71 / T_{e}} \sigma$ from $^{61}$ \\
\hline 1.10 & $\mathrm{e}^{-}+\mathrm{NH}_{3} \rightarrow \mathrm{NH}_{3}^{+}+2 \mathrm{e}^{-}$ & $1.5 \times 10^{-14} T_{e}^{0.40} \times e^{-13.61 / T_{e}} \sigma$ from $^{63}$ \\
\hline 1.11 & $\mathrm{e}^{-}+\mathrm{NH}_{3} \rightarrow \mathrm{NH}_{2}^{+}+\mathrm{H}+2 \mathrm{e}^{-}$ & $1.6 \times 10^{-14} T_{e}^{0.34} \times e^{-15.41 / T_{e}} \sigma$ from $^{63}$ \\
\hline 1.12 & $\mathrm{e}^{-}+\mathrm{NH}_{3} \rightarrow \mathrm{NH}^{+}+2 \mathrm{H}+2 \mathrm{e}^{-}$ & $5.4 \times 10^{-16} T_{e}^{0.37} \times e^{-26.06 / T_{e}} \sigma$ from $^{63}$ \\
\hline 1.13 & $\mathrm{e}^{-}+\mathrm{NH}_{3} \rightarrow \mathrm{N}^{+}+\mathrm{H}+\mathrm{H}_{2}+2 \mathrm{e}^{-}$ & $8.8 \times 10^{-17} T_{e}^{0.59} \times e^{-29.00 / T_{e}} \sigma$ from $^{64}$ \\
\hline 1.14 & $\mathrm{e}^{-}+\mathrm{NH}_{3} \rightarrow \mathrm{H}^{+}+\mathrm{NH}_{2}+2 \mathrm{e}^{-}$ & $1.3 \times 10^{-16} T_{e}^{0.47} \times e^{-28.55 / T_{e}} \sigma$ from $^{64}$ \\
\hline 1.15 & $\mathrm{e}^{-}+\mathrm{NH}_{2} \rightarrow \mathrm{NH}_{2}^{+}+2 \mathrm{e}^{-}$ & $1.3 \times 10^{-14} T_{e}^{0.50} \times e^{-12.40 / T_{e}} \sigma$ from $^{63}$ \\
\hline 1.16 & $\mathrm{e}^{-}+\mathrm{NH}_{2} \rightarrow \mathrm{NH}^{+}+\mathrm{H}+2 \mathrm{e}^{-}$ & $2.2 \times 10^{-14} T_{e}^{0.21} \times e^{-17.97 / T_{e}} \sigma$ from $^{63}$ \\
\hline 1.17 & $\mathrm{e}^{-}+\mathrm{NH} \rightarrow \mathrm{NH}^{+}+2 \mathrm{e}^{-}$ & $2.1 \times 10^{-14} T_{e}^{0.37} \times e^{-15.49 / T_{e}} \sigma$ from $^{63}$ \\
\hline 1.18 & $\mathrm{e}^{-}+\mathrm{NH} \rightarrow \mathrm{N}^{+}+\mathrm{H}+2 \mathrm{e}^{-}$ & $7.6 \times 10^{-15} T_{e}^{0.29} \times e^{-16.82 / T_{e}} \sigma$ from $^{63}$ \\
\hline 1.19 & $\mathrm{e}^{-}+\mathrm{NH}_{3} \rightarrow \mathrm{NH}_{2}+\mathrm{H}+\mathrm{e}^{-}$ & $4.2 \times 10^{-14} T_{e}^{-0.19} \times e^{-7.59 / T_{e}} \sigma$ from $^{65}$ \\
\hline 1.20 & $\mathrm{e}^{-}+\mathrm{NH}_{3} \rightarrow \mathrm{NH}+2 \mathrm{H}+\mathrm{e}^{-}$ & $1.3 \times 10^{-14} T_{e}^{0.38} \times e^{-11.06 / T_{e}} \sigma$ from $^{65}$ \\
\hline 1.21 & $\mathrm{e}^{-}+\mathrm{NH}_{3} \rightarrow \mathrm{NH}+\mathrm{H}_{2}+\mathrm{e}^{-}$ & $4.1 \times 10^{-14} T_{e}^{-0.26} \times e^{-4.84 / T_{e}} \sigma$ from $^{65}$ \\
\hline 1.22 & $\mathrm{e}^{-}+\mathrm{NH}_{2} \rightarrow \mathrm{NH}+\mathrm{H}+\mathrm{e}^{-}$ & $4.5 \times 10^{-14} T_{e}^{-0.22} \times e^{-7.61 / T_{e}} \sigma$ from $^{11}$ \\
\hline 1.23 & $\mathrm{e}^{-}+\mathrm{NH}_{2} \rightarrow \mathrm{N}+\mathrm{H}_{2}+\mathrm{e}^{-}$ & $1.5 \times 10^{-14} T_{e}^{0.38} \times e^{-11.44 / T_{e}} \sigma$ from $^{11}$ \\
\hline 1.24 & $\mathrm{e}^{-}+\mathrm{NH} \rightarrow \mathrm{N}+\mathrm{H}+\mathrm{e}^{-}$ & $4.7 \times 10^{-14} T_{e}^{-0.22} \times e^{-7.69 / T_{e}} \sigma$ from $^{11}$ \\
\hline 1.25 & $\mathrm{e}^{-}+\mathrm{H}_{2}^{+} \rightarrow \mathrm{H}^{+}+\mathrm{H}+\mathrm{e}^{-}$ & $1.5 \times 10^{-13} \times e^{-1.97 / T_{e}}$ \\
\hline
\end{tabular}

TABLE II. Reaction set with rate coefficients $K$ for electron collisions with index $k\left(T_{e}\right.$ in $\left.\mathrm{eV}\right)$.

considered.

11. In the model the densities of the background gas species are not affected by the plasma and, therefore, kept constant for the discharge. This is based on the fact that the degree of dissociation $(<10 \%)$ and also the degree of ionization $\left(\approx 10^{-4}\right)$ are very low. One indication that this assumption is fulfilled is that the measured pressure after plasma ignition does not significantly change $(<4 \%)$. The change of $<4 \%$ is attributed to $\mathrm{NH}_{3}$ production. As input parameters, the measured partial pressure fractions $f_{j}$ during plasma operation are used.

\section{B. Electron and ion-molecule collisions}

The rate coefficients $K_{k}$ for electron collisions are calculated from the corresponding cross sections $\sigma_{k}$ by averaging the product $\sigma_{k} \times v_{e}\left(v_{e}\right.$ - electron velocity) over a Maxwellian electron energy distribution function (for details, see Ref. ${ }^{23}$ ). The values for the considered electron 


\begin{tabular}{ccl}
$k$ & Reaction & $K\left(\mathrm{~m}^{3} \mathrm{~s}^{-1}\right)$ Reference \\
\hline 2.1 & $\mathrm{H}_{2}^{+}+\mathrm{H}_{2} \rightarrow \mathrm{H}_{3}^{+}+\mathrm{H}$ & $2.0 \times 10^{-15} 66$ \\
2.2 & $\mathrm{ArH}^{+}+\mathrm{H}_{2} \rightarrow \mathrm{H}_{3}^{+}+\mathrm{Ar}$ & $6.3 \times 10^{-16} 66$ \\
2.3 & $\mathrm{H}_{2}^{+}+\mathrm{Ar} \rightarrow \mathrm{ArH}^{+}+\mathrm{H}$ & $2.1 \times 10^{-15} 66$ \\
2.4 & $\mathrm{H}_{2}^{+}+\mathrm{Ar} \rightarrow \mathrm{Ar}^{+}+\mathrm{H}_{2}$ & $2.0 \times 10^{-16} 66$ \\
2.5 & $\mathrm{H}_{3}^{+}+\mathrm{Ar} \rightarrow \mathrm{ArH}^{+}+\mathrm{H}_{2}$ & $3.7 \times 10^{-16} 66$ \\
2.6 & $\mathrm{Ar}^{+}+\mathrm{H}_{2} \rightarrow \mathrm{ArH}^{+}+\mathrm{H}$ & $8.7 \times 10^{-16} 66$ \\
2.7 & $\mathrm{Ar}^{+}+\mathrm{H}_{2} \rightarrow \mathrm{H}_{2}^{+}+\mathrm{Ar}$ & $1.8 \times 10^{-17} 66$ \\
2.8 & $\mathrm{~N}^{+}+\mathrm{N}_{2} \rightarrow \mathrm{N}_{2}^{+}+\mathrm{N}$ & $2.0 \times 10^{-17} 67$ \\
2.9 & $\mathrm{~N}_{2}^{+}+\mathrm{N} \rightarrow \mathrm{N}^{+}+\mathrm{N} 2$ & $1.0 \times 10^{-17} 66$ \\
2.10 & $\mathrm{Ar}^{+}+\mathrm{N}_{2} \rightarrow \mathrm{N}_{2}^{+}+\mathrm{Ar}$ & $1.1 \times 10^{-17} 66$ \\
2.11 & $\mathrm{~N}_{2}^{+}+\mathrm{Ar} \rightarrow \mathrm{Ar}^{+}+\mathrm{N} \mathrm{N}_{2}$ & $2.0 \times 10^{-19} 66$ \\
2.12 & $\mathrm{~N}_{2}^{+}+\mathrm{H}_{2} \rightarrow \mathrm{N}_{2} \mathrm{H}^{+}+\mathrm{H}$ & $2.0 \times 10^{-15} 66$ \\
2.13 & $\mathrm{H}_{2}^{+}+\mathrm{N}_{2} \rightarrow \mathrm{N}_{2} \mathrm{H}^{+}+\mathrm{H}$ & $2.0 \times 10^{-15} 66$ \\
2.14 & $\mathrm{H}_{3}^{+}+\mathrm{N}_{2} \rightarrow \mathrm{N}_{2} \mathrm{H}^{+}+\mathrm{H}_{2}$ & $1.9 \times 10^{-15} 66$ \\
2.15 & $\mathrm{H}_{3}^{+}+\mathrm{NH}_{3} \rightarrow \mathrm{NH}_{4}^{+}+\mathrm{H} 2$ & $4.4 \times 10^{-15} 66$ \\
2.16 & $\mathrm{~N}^{+}+\mathrm{H}_{2} \rightarrow \mathrm{NH}^{+}+\mathrm{H}$ & $5.0 \times 10^{-16} 66$ \\
2.17 & $\mathrm{NH}_{2}^{+}+\mathrm{H}_{2} \rightarrow \mathrm{NH}_{3}^{+}+\mathrm{H}$ & $2.0 \times 10^{-16} 66$ \\
2.18 & $\mathrm{H}_{2}^{+}+\mathrm{N}^{+} \rightarrow \mathrm{N}^{+}+\mathrm{H}_{2}$ & $5.0 \times 10^{-16} 26$ \\
$2.19 \mathrm{Ar}^{+}+\mathrm{NH}_{2} \rightarrow \mathrm{NH}^{+}+\mathrm{H}+\mathrm{Ar} 5.5 \times 10^{-17} 26$ \\
2.20 & $\mathrm{H}^{+}+\mathrm{NH}_{3} \rightarrow \mathrm{NH}_{3}^{+}+\mathrm{H}$ & $5.2 \times 10^{-15} 66$ \\
2.21 & $\mathrm{H}_{2}^{+}+\mathrm{NH}_{3} \rightarrow \mathrm{NH}_{3}^{+}+\mathrm{H}_{2}$ & $5.7 \times 10^{-15} 66$ \\
2.22 & $\mathrm{H}_{3}^{+}+\mathrm{N}_{2} \rightarrow \mathrm{NH}^{+}+\mathrm{H}_{2}$ & $2.6 \times 10^{-16} 66$ \\
2.23 & $\mathrm{H}_{3}^{+}+\mathrm{N}_{2} \rightarrow \mathrm{NH}_{2}^{+}+\mathrm{H}$ & $3.9 \times 10^{-16} 66$ \\
2.24 & $\mathrm{~N}^{+}+\mathrm{NH}_{3} \rightarrow \mathrm{NH}_{2}^{+}+\mathrm{NH}$ & $4.7 \times 10^{-16} 66$ \\
2.25 & $\mathrm{~N}^{+}+\mathrm{NH}_{3} \rightarrow \mathrm{NH}_{3}^{+}+\mathrm{N}$ & $1.7 \times 10^{-15} 66$
\end{tabular}

TABLE III. Reaction set for ion-molecule reactions $k$.

collisions are compiled in Tab. II. From here on the rate coefficients $K_{k}$ will be labeled according to the index $k$ for the corresponding reaction listed in Tabs. II - IX. Yoon et al. ${ }^{58}$ and Itikawa ${ }^{61}$ compiled a collection of recommended values of cross sections for electron collisions with hydrogen and nitrogen molecules, respectively. We consider these data as the presently most reliable data set. Shah et al. ${ }^{59}$ and Wetzel et al. ${ }^{60}$ measured electron ionization cross sections and compared their results to existing literature data. Their values agree with published data within $15 \%$. For the ionization cross sections of $\mathrm{NH}_{3}$ there exist only few publications (Tarnovsky et al. ${ }^{63}$ and Mrk et al. ${ }^{64}$ ), for $\mathrm{NH}_{2}$ and $\mathrm{NH}$ there is only one publication (Tarnovsky et al. ${ }^{63}$ ). The dissociation of $\mathrm{NH}_{3}$ leads to 3 products (reactions 1.19-1.21 in Table II). The corresponding dissociation cross sections are taken from Yousfi and Benabdessadok ${ }^{65}$. The dissociation cross sections for $\mathrm{NH}_{2}$ and $\mathrm{NH}$ are taken from van Laer et al. ${ }^{11}$. The rate coefficient of reaction 1.25 whose reaction is of minor importance is directly taken from Ref. ${ }^{57}$.

The used $K_{k}$ 's for ion-molecule reactions are listed in Tables III and IV. Where possible, the rate coefficients are taken from a compilation by Anicich ${ }^{66}$. Anicich provides a collection of recommended values of rate coefficients for a wealth of bimolecular ion-molecule reactions 


\begin{tabular}{ccl}
$k$ & Reaction & $K\left(\mathrm{~m}^{3} \mathrm{~s}^{-1}\right)$ Reference \\
\hline 2.26 & $\mathrm{~N}^{+}+\mathrm{NH}_{3} \rightarrow \mathrm{N}_{2} \mathrm{H}^{+}+\mathrm{H}_{2}$ & $2.1 \times 10^{-16} 66$ \\
2.27 & $\mathrm{NH}^{+}+\mathrm{H}_{2} \rightarrow \mathrm{H}_{3}^{+}+\mathrm{N}$ & $1.8 \times 10^{-16} 66$ \\
2.28 & $\mathrm{NH}^{+}+\mathrm{H}_{2} \rightarrow \mathrm{NH}_{2}^{+}+\mathrm{H}$ & $1.0 \times 10^{-15} 66$ \\
2.29 & $\mathrm{NH}^{+}+\mathrm{NH}_{3} \rightarrow \mathrm{NH}_{3}^{+}+\mathrm{NH}$ & $1.8 \times 10^{-15} 66$ \\
2.30 & $\mathrm{NH}^{+}+\mathrm{NH}_{3} \rightarrow \mathrm{NH}_{4}^{+}+\mathrm{N}$ & $6.0 \times 10^{-16} 66$ \\
2.31 & $\mathrm{NH}^{+}+\mathrm{N}_{2} \rightarrow \mathrm{N}_{2} \mathrm{H}^{+}+\mathrm{N}$ & $6.5 \times 10^{-16} 66$ \\
2.32 & $\mathrm{NH}_{2}^{+}+\mathrm{NH}_{3} \rightarrow \mathrm{NH}_{3}^{+}+\mathrm{NH}_{2}$ & $1.2 \times 10^{-15} 66$ \\
2.33 & $\mathrm{NH}_{2}^{+}+\mathrm{NH}_{3} \rightarrow \mathrm{NH}_{4}^{+}+\mathrm{NH}$ & $1.2 \times 10^{-15} 66$ \\
2.34 & $\mathrm{NH}_{3}^{+}+\mathrm{H}_{2} \rightarrow \mathrm{NH}_{4}^{+}+\mathrm{H}$ & $4.4 \times 10^{-19} 66$ \\
2.35 & $\mathrm{NH}_{3}^{+}+\mathrm{NH}_{3} \rightarrow \mathrm{NH}_{4}^{+}+\mathrm{NH}$ & $2.1 \times 10^{-15} 66$ \\
2.36 & $\mathrm{~N}_{2}^{+}+\mathrm{NH}_{3} \rightarrow \mathrm{NH}_{3}^{+}+\mathrm{N}_{2}$ & $2.0 \times 10^{-15} 66$ \\
2.37 & $\mathrm{~N}_{2} \mathrm{H}^{+}+\mathrm{H}_{2} \rightarrow \mathrm{H}_{3}^{+}+\mathrm{N}_{2}$ & $5.1 \times 10^{-24} 66$ \\
2.38 & $\mathrm{~N}_{2} \mathrm{H}^{+}+\mathrm{NH}_{3} \rightarrow \mathrm{NH}_{4}^{+}+\mathrm{N}_{2}$ & $2.3 \times 10^{-15} 66$ \\
2.39 & $\mathrm{Ar}^{+}+\mathrm{NH}_{3} \rightarrow \mathrm{NH}_{3}^{+}+\mathrm{Ar}$ & $1.6 \times 10^{-15} 66$ \\
2.40 & $\mathrm{ArH}^{+}+\mathrm{NH}_{3} \rightarrow \mathrm{NH}_{3}^{+}+\mathrm{H}+\mathrm{Ar} 5.3 \times 10^{-16} 66$ \\
2.41 & $\mathrm{ArH}^{+}+\mathrm{NH}_{3} \rightarrow \mathrm{NH}_{4}^{+}+\mathrm{Ar}$ & $1.6 \times 10^{-15} 66$ \\
2.42 & $\mathrm{ArH}^{+}+\mathrm{N}_{2} \rightarrow \mathrm{N}_{2} \mathrm{H}^{+}+\mathrm{Ar}$ & $8.0 \times 10^{-16} 66$ \\
2.43 & $\mathrm{~N}^{+}+\mathrm{H} \rightarrow \mathrm{H}^{+}+\mathrm{N}$ & $2.0 \times 10^{-16} 26$ \\
2.44 & $\mathrm{H}_{2}^{+}+\mathrm{NH}_{3} \rightarrow \mathrm{NH}_{4}^{+}+\mathrm{H}$ & $5.0 \times 10^{-17} 26$ \\
2.45 & $\mathrm{H}_{2}^{+}+\mathrm{NH}_{2} \rightarrow \mathrm{NH}_{3}^{+}+\mathrm{H}$ & $5.0 \times 10^{-17} 26$ \\
2.46 & $\mathrm{H}_{2}^{+}+\mathrm{NH}_{2} \rightarrow \mathrm{NH}_{2}^{+}+\mathrm{H}$ & $5.0 \times 10^{-17} 26$ \\
2.47 & $\mathrm{NH}^{+}+\mathrm{NH}_{2} \rightarrow \mathrm{NH}_{2}^{+}+\mathrm{NH}$ & $1.8 \times 10^{-15} 26$ \\
2.48 & $\mathrm{Ar}^{+}+\mathrm{NH}_{3} \rightarrow \mathrm{NH}_{2}^{+}+\mathrm{H}+\mathrm{Ar}$ & $5.5 \times 10^{-17} 26$ \\
2.49 & $\mathrm{Ar}^{+}+\mathrm{NH}_{3} \rightarrow \mathrm{ArH}^{+}+\mathrm{NH}$ & $9.2 \times 10^{-17} 26$
\end{tabular}

TABLE IV. Reaction set for ion-molecule reactions $k$ (continuation).

\begin{tabular}{|l|l|l|}
\hline $\mathrm{H}^{+}+$wall $\rightarrow \mathrm{H}$ & $\mathrm{NH}^{+}+$wall $\rightarrow \mathrm{NH}$ & $\mathrm{N}_{2}^{+}+$wall $\rightarrow \mathrm{N}_{2}$ \\
$\mathrm{H}_{2}^{+}+$wall $\rightarrow \mathrm{H}_{2}$ & $\mathrm{NH}_{2}^{+}+$wall $\rightarrow \mathrm{NH}_{2}$ \\
$\mathrm{H}_{3}^{+}+$wall $\rightarrow \mathrm{H}_{2}+\mathrm{H}$ & $\mathrm{NH}_{2}^{+} \mathrm{H}^{+}+$wall $\rightarrow \mathrm{N}_{2}+\mathrm{H}$ \\
$\mathrm{N}^{+}+$wall $\rightarrow \mathrm{N}$ & $\mathrm{NH}_{4}^{+}+$wall $\rightarrow \mathrm{NH}_{3}+\mathrm{H}$ & $\mathrm{Ar}^{+}+$wall $\rightarrow \mathrm{Ar}$ \\
\hline
\end{tabular}

TABLE V. Considered ion wall loss reactions.

for a gas temperature of $300 \mathrm{~K}$. The gas temperature in the here investigated plasma is 460 K (see Sec. II C). However, this should not significantly influence the rate coefficients due to the fact that in most cases $K$ is independent of $T_{g}$ (see Ref. ${ }^{23}$ ). Reaction coefficients which are not contained in Ref. ${ }^{66}$ are taken from the following sources: Arakoni et al. ${ }^{26}$ and Tao et al. ${ }^{67}$. 


\section{Wall loss for ions}

We assume that ions reaching the wall recombine with a probability of 1 . A compilation of the ion loss processes to the wall is shown in Table V. For the case of dissociative recombination the produced atomic hydrogen is assumed to be reflected from the surface with a probability of 1 . The rate coefficients $K_{w i}$ for the loss of positive ions to the walls are based on the uniform density discharge model for low and intermediate pressures of Lieberman and Lichtenberg ${ }^{68}$ :

$$
K_{w i}=\frac{2 h_{l, i}}{l_{e l}} \sqrt{\frac{e T_{e}}{M_{i}}}
$$

$M_{i}$ denotes the ion mass. The coefficient $h_{l, i}$ is given by ${ }^{68,69}$ :

$$
h_{l, i}=\frac{0.86}{\sqrt{3+\frac{l_{e l}}{2 \lambda_{i}}}} .
$$

$\lambda_{i}$ is the mean free path length for ions traversing the background gas $j$ with density $n_{j}$ :

$$
1 / \lambda_{i}=\sum_{j, k} \sigma_{k} n_{j}
$$

$\sigma_{k}$ denotes the cross section for the collision (reaction $k$ ) of the ion with the background gas atom or molecule $j$. This collisions can be elastic, but also charge exchange collisions and proton transfers can occur. The values for individual $\sigma_{k}$ 's are shown in Table VI for a relative energy of $E_{i j}=1.5 k_{B} T_{g}$ using the gas temperature of $T_{g}=460 \mathrm{~K}$ as obtained experimentally (see Sect. II C). Most cross sections and rate coefficients for the here considered reactions are available in the literature. However, some $\sigma$ and $K$ could not be found and, therefore, assumptions about the unavailable $\sigma$ have to be made as these collisions cannot be neglected. For the collisions occurring in $\mathrm{H}_{2}$-Ar plasmas $\sigma_{k}$ values are taken from Bogaerts and Gijbels ${ }^{70}$ (label 'a' in Table VI). A detailed discussion of the reliability of these values was presented in Ref. ${ }^{23}$. For collisions of $\mathrm{N}^{+}$and $\mathrm{N}_{2}^{+}$with $\mathrm{N}_{2}, \sigma(E)$ values of Phelps ${ }^{71}$ are used (label 'b' in Table VI). For those collisions where $K$ is available in Tables III and IV (label 'c' in Table VI), $\sigma$ is calculated from this corresponding $K$ according to $K=\sigma\left(E_{i j}\right) \times\left(2 E_{i j} / \mu_{i j}\right)^{0.5}$ $\left(\mu_{i j} \text { - reduced mass }\right)^{23}$. For the collisions of $\mathrm{NH}_{x}^{+}(x=2,3,4)$ with $\mathrm{N}_{2}$ and $\mathrm{NH}_{4}^{+}$with $\mathrm{H}_{2}$ we used an estimation of Anicich ${ }^{66}$, i.e., $\sigma=1 \times 10^{-23} \mathrm{~m}^{2}$, because they found that the corresponding $K$ 's are small for these reactions. For collisions of $\mathrm{NH}_{x}^{+}(x=0 ; . . ; 4)$ and $\mathrm{N}_{2} \mathrm{H}^{+}$with Ar no values for $\sigma$ or $K$ can be found (label 'd' in Table VI). In Refs. ${ }^{72,73}$ it was discussed that the collision behavior between ions with $\mathrm{N}_{2}$ and ions with Ar is similar which was also confirmed by the theoretically calculated rate coefficients in Ref. ${ }^{74}$. Therefore, we used the missing $\sigma$ or $K$ for collisions of $\mathrm{NH}_{x}^{+}(x=2,3,4)$ and $\mathrm{NH}_{4}^{+}$with Ar from those values available for $\mathrm{N}_{2}$. In Table VI this is indicated by 'd'. Similarly, for the collision of $\mathrm{H}^{+}$with $\mathrm{N}_{2} \sigma$ is assumed to be the same as for $\mathrm{H}^{+}$with Ar. It should be noted that for the labels 'a' and 'b' in Table VI elastic collisions are taken into account, whereas for the labels 'c' and 'd' elastic collisions are not taken into account because no corresponding $\sigma$ or 


\begin{tabular}{|c|c|c|c|c|c|}
\hline & $j=\mathrm{H}_{2}$ & $\mathrm{~N}_{2}$ & $\mathrm{Ar}$ & $\mathrm{NH}_{3}$ & \\
\hline$i=\mathrm{H}^{+}$ & $9.8 \quad(\mathrm{a})$ & 8.6 & 8.6 & 16 & (c) \\
\hline $\mathrm{H}_{2}^{+}$ & $7.1 \quad$ (a) & 8.8 & (a) & 24 & (c) \\
\hline $\mathrm{H}_{3}^{+}$ & $8.5 \quad$ (a) & 9.8 & 9.5 & 23 & (c) \\
\hline $\mathrm{N}^{+}$ & $2.1 \quad$ (c) & 12 & (d) & 21 & (c) \\
\hline $\mathrm{NH}^{+}$ & $5.2 \quad(\mathrm{c})$ & $6.5 \quad(\mathrm{c})$ & $6.9 \quad(\mathrm{~d})$ & 22 & (c) \\
\hline $\mathrm{NH}_{2}^{+}$ & $0.8 \quad(c)$ & $10^{-4}(\mathrm{~d})$ & $10^{-4}(\mathrm{~d})$ & 21 & (c) \\
\hline $\mathrm{NH}_{3}^{+}$ & $0.002(\mathrm{c})$ & $10^{-4}(\mathrm{~d})$ & $10^{-4}(\mathrm{~d})$ & 20 & (c) \\
\hline $\mathrm{NH}_{4}^{+}$ & $10^{-5} \quad(\mathrm{~d})$ & $10^{-4}(\mathrm{~d})$ & $10^{-4}(\mathrm{~d})$ & 5.7 & (c) \\
\hline $\mathrm{N}_{2}^{+}$ & $8.8 \quad(c)$ & $30 \quad(b)$ & $0.003(\mathrm{c})$ & 20 & (c) \\
\hline $\mathrm{N}_{2}^{2} \mathrm{H}^{+}$ & $10^{-8} \quad(\mathrm{c})$ & (c) & $54 \quad(d)$ & 24 & (c) \\
\hline $\mathrm{Ar}^{+}$ & $4.6 \quad(\mathrm{a})$ & $0.14 \quad(\mathrm{c})$ & (a) & 18 & (c) \\
\hline $\mathrm{ArH}^{+}$ & (a) & $10 \quad(c)$ & (a) & 24 & (c) \\
\hline
\end{tabular}

TABLE VI. Total cross sections $\sum_{k} \sigma$ in $10^{-19} \mathrm{~m}^{2}$ for collisions between ions $i$ with background gas species $j$ for a gas temperature of $460 \mathrm{~K}$. Reference: a $-\sigma$ taken from Bogaerts and Gijbels ${ }^{70}$; b - $\sigma$ taken from Phelps ${ }^{71}$; c - $\sigma$ determined from corresponding $K$ (see Tables III and IV); d assumed values (see text).

\begin{tabular}{llll}
$k$ & Reaction & $K\left(\mathrm{~m}^{3} \mathrm{~s}^{-1}\right),\left(\mathrm{s}^{-1}\right)$ & Reference \\
\hline 3.1 & $\mathrm{e}^{-}+\mathrm{Ar} \rightarrow \mathrm{Ar}_{\text {meta }}+\mathrm{e}^{-}$ & $5.0 \times 10^{-15} \times e^{-12.64 / T_{e}}$ & 57 \\
3.2 & $\mathrm{e}^{-}+\mathrm{Ar} \rightarrow \operatorname{Ar}(4 p)+\mathrm{e}^{-}$ & $2.1 \times 10^{-14} \times e^{-13.13 / T_{e}}$ & 57 \\
3.3 & $\operatorname{Ar}_{r} \rightarrow \operatorname{Ar}+h \nu$ & $1.0 \times 10^{5}$ & 57 \\
3.4 & $\operatorname{Ar}(4 p) \rightarrow \operatorname{Ar}_{r}+h \nu$ & $3.0 \times 10^{7}$ & 57 \\
3.5 & $\operatorname{Ar}(4 p) \rightarrow \operatorname{Ar}_{\text {meta }}+h \nu$ & $3.0 \times 10^{7}$ & 57 \\
3.6 & $\operatorname{Ar}_{\text {meta }}+$ wall $\rightarrow \operatorname{Ar}$ & $K_{w \operatorname{Ar}_{\text {meta }}}\left(\beta_{\text {Ar }_{\text {meta }}}=1\right)$ & 75 \\
\hline
\end{tabular}

TABLE VII. Reaction set for excited argon with rate coefficients $K$ for a reaction $k\left(T_{e}\right.$ in $\left.\mathrm{eV}\right)$.

$K$ data were reported in the literature. In this case the value in Table VI is a lower limit of the total cross section $\sum_{k} \sigma$. However, the influence of $\sum_{k} \sigma$ on $K_{w i}$ is small as can be seen in Eq. 5: $K_{w i}$ has an offset of $0.86 / \sqrt{3}$ for the limit $\sum_{k} \sigma \rightarrow 0$ and varies only with the square root for higher $\sum_{k} \sigma$ (see Eq. 6).

\section{Further reaction sets}

In this section, reactions involving excited species are presented and briefly explained. Metastables have a relatively long lifetime and can, therefore, collide quite often with the background gas $j$. As metastables carry potential energy of several $\mathrm{eV}$, in a collision this energy can be transferred to $j$ so that $j$ can dissociate. To assess whether or not metastable argon $\operatorname{Ar}_{\text {meta }}$, metastable molecular nitrogen $\mathrm{N}_{2}(A)$, and the metastables $\mathrm{N}(D)$ and $\mathrm{N}(P)$ of atomic nitrogen influence the dissociation of molecules, they are considered in a simplified collisional-radiative model ${ }^{57,76}$. This model takes into account only the most important electronically excited states. The following species are considered: 


\begin{tabular}{|c|c|c|c|}
\hline$k$ & Reaction & $K\left(\mathrm{~m}^{3} \mathrm{~s}^{-1}\right)$ & Reference \\
\hline 4.1 & $\mathrm{e}^{-}+\mathrm{N}_{2} \rightarrow \mathrm{N}_{2}(A)+\mathrm{e}^{-}$ & $1.2 \times 10^{-14} \times e^{-7.34 / T_{e}}$ & 76 \\
\hline 4.2 & $\mathrm{e}^{-}+\mathrm{N}_{2} \rightarrow \mathrm{N}_{2}(B)+\mathrm{e}^{-}$ & $5.6 \times 10^{-15} \times e^{-6.81 / T_{e}}$ & 76 \\
\hline 4.3 & $\mathrm{e}^{-}+\mathrm{N}_{2} \rightarrow \mathrm{N}_{2}(C)+\mathrm{e}^{-}$ & $6.4 \times 10^{-15} \times e^{-9.87 / T_{e}}$ & 76 \\
\hline 4.4 & $\mathrm{e}^{-}+\mathrm{N}_{2} \rightarrow \mathrm{N}_{2}(a)+\mathrm{e}^{-}$ & $5.1 \times 10^{-15} \times e^{-11.69 / T_{e}}$ & 76 \\
\hline 4.5 & $\mathrm{e}^{-}+\mathrm{N}_{2}(A) \rightarrow \mathrm{N}_{2}^{+}+2 \mathrm{e}^{-}$ & $8.3 \times 10^{-15} \times e^{-12.84 / T_{e}}$ & 76 \\
\hline 4.6 & $\mathrm{e}^{-}+\mathrm{N}_{2}(B) \rightarrow \mathrm{N}_{2}^{+}+2 \mathrm{e}^{-}$ & $2.1 \times 10^{-14} \times e^{-11.0 / T_{e}}$ & 76 \\
\hline 4.7 & $\mathrm{e}^{-}+\mathrm{N}_{2}(a) \rightarrow \mathrm{N}_{2}^{+}+2 \mathrm{e}^{-}$ & $4.3 \times 10^{-14} \times e^{-10.32 / T_{e}}$ & 76 \\
\hline 4.8 & $\mathrm{e}^{-}+\mathrm{N} \rightarrow \mathrm{N}(D)+\mathrm{e}^{-}$ & $2.7 \times 10^{-14} T_{e}^{-0.4} \times e^{-3.35 / T_{e}}$ & 76 \\
\hline 4.9 & $\mathrm{e}^{-}+\mathrm{N} \rightarrow \mathrm{N}(P)+\mathrm{e}^{-}$ & $9.1 \times 10^{-14} T_{e}^{-0.45} \times e^{-4.80 / T_{e}}$ & 76 \\
\hline 4.10 & $\mathrm{e}^{-}+\mathrm{N}(D) \rightarrow \mathrm{N}^{+}+2 \mathrm{e}^{-}$ & $1.0 \times 10^{-14} T_{e}^{-0.36} \times e^{-0.83 / T_{e}}$ & 76 \\
\hline 4.11 & $\mathrm{e}^{-}+\mathrm{N}(P) \rightarrow \mathrm{N}^{+}+2 \mathrm{e}^{-}$ & $5.5 \times 10^{-15} T_{e}^{-0.41} \times e^{-1.05 / T_{e}}$ & 76 \\
\hline 4.12 & $\mathrm{~N}_{2}(a)+\mathrm{N}_{2}(A) \rightarrow \mathrm{N}_{2}^{+}+\mathrm{e}^{-}$ & $9.0 \times 10^{-18}$ & 76 \\
\hline 4.13 & $2 \mathrm{~N}_{2}(a) \rightarrow \mathrm{N}_{2}^{+}+\mathrm{e}^{-}$ & $2.5 \times 10^{-17}$ & 76 \\
\hline 4.14 & $\mathrm{~N}_{2}(A)+\mathrm{N} \rightarrow \mathrm{N}(P)+\mathrm{N}_{2}$ & $5.0 \times 10^{-16}$ & 76 \\
\hline 4.15 & $\mathrm{~N}_{2}(A)+\mathrm{N}_{2} \rightarrow 2 \mathrm{~N}_{2}$ & $4.0 \times 10^{-17}$ & 76 \\
\hline 4.16 & $\mathrm{~N}(P)+\mathrm{N}(D) \rightarrow \mathrm{N}_{2}^{+}+\mathrm{e}^{-}$ & $3.0 \times 10^{-18}$ & 76 \\
\hline 4.17 & $\mathrm{~N}_{2}(B) \rightarrow \mathrm{N}_{2}(A)+h \nu$ & $2.0 \times 10^{5}$ & 76 \\
\hline 4.18 & $\mathrm{~N}_{2}(C) \rightarrow \mathrm{N}_{2}(B)+h \nu$ & $2.7 \times 10^{7}$ & 76 \\
\hline 4.19 & $\mathrm{~N}_{2}(A)+$ wall $\rightarrow \mathrm{N}_{2}$ & $K_{w \mathrm{~N}_{2}(A)}\left(\beta_{\mathrm{N}_{2}(A)}=1\right)$ & 77 \\
\hline 4.20 & $\mathrm{~N}_{2}(a)+$ wall $\rightarrow \mathrm{N}_{2}$ & $K_{w \mathrm{~N}_{2}(a)}\left(\beta_{\mathrm{N}_{2}(a)}=1\right)$ & 76 \\
\hline 4.21 & $\mathrm{~N}(D)+$ wall $\rightarrow 0.5 \mathrm{~N}_{2}$ & $K_{w \mathrm{~N}(D)}=\left(t_{w \mathrm{~N}}\right)^{-1}$ & \\
\hline 4.22 & $\mathrm{~N}(P)+$ wall $\rightarrow 0.5 \mathrm{~N}_{2}$ & $K_{w \mathrm{~N}(P)}=\left(t_{w \mathrm{~N}}\right)^{-1}$ & \\
\hline
\end{tabular}

TABLE VIII. Reaction set for excited nitrogen with rate coefficients $K$ for a reaction $k\left(T_{e}\right.$ in $\left.\mathrm{eV}\right)$. $t_{w \mathrm{~N}}$ denotes the wall loss time of $\mathrm{N}$ (see Sec. IV).

For the reaction set of excited Ar:

- $\mathrm{Ar}_{\text {meta }}$ consisting of the excited, metastable levels $1 s^{5}$ and $1 s^{3}$ in Paschen's notation

- $\mathrm{Ar}_{r}$ consisting of the excited levels $1 s^{4}$ and $1 s^{2}$

- $\operatorname{Ar}(2 p)$ consisting of the excited levels $2 p^{1}$ to $2 p^{10}$,

for the reaction set of excited $\mathrm{N}_{2}$ :

- $\mathrm{N}_{2}(A)$ which denotes the excited, metastable level $\mathrm{N}_{2}\left(A^{3} \Sigma_{u}^{+}\right)$

- $\mathrm{N}_{2}(B)$ which denotes the excited level $\mathrm{N}_{2}\left(B^{3} \Pi_{g}\right)$

- $\mathrm{N}_{2}(C)$ which denotes the excited level $\mathrm{N}_{2}\left(C^{3} \Pi_{u}\right)$

- $\mathrm{N}_{2}\left(a^{\prime}\right)$ which denotes the excited level $\mathrm{N}_{2}\left(a^{\prime} \Sigma_{u}\right)$,

and for the reaction set of excited $\mathrm{N}$ :

- $\mathrm{N}(D)$ which denotes the excited, metastable level $\mathrm{N}\left({ }^{2} D\right)$

- $\mathrm{N}(P)$ which denotes the excited, metastable level $\mathrm{N}\left({ }^{2} P\right)$.

The considered reactions are summarized in Tables VII, VIII, and IX together with the corresponding rate coefficients. They are based on the reaction sets of Kimura and Kasugai $^{57,76}$. Kimura and Kasugai take into account 16 reactions for the excited argon atom and 45 reactions for the excited molecular and atomic nitrogen (without mixed reactions of the type $\mathrm{Ar}^{*}+\mathrm{N}_{2}$ ). In a preparatory study (see Ref. ${ }^{78}$ ) we found that these reaction sets 


\begin{tabular}{llll}
$k$ & Reaction & $K\left(\mathrm{~m}^{3} \mathrm{~s}^{-1}\right)$ & Reference \\
\hline 5.1 & $\mathrm{Ar}_{\text {meta }}+\mathrm{H}_{2} \rightarrow 2 \mathrm{H}+\mathrm{Ar}$ & $1.1 \times 10^{-16}$ & 57 \\
5.2 & $\mathrm{Ar}_{r}+\mathrm{H}_{2} \rightarrow 2 \mathrm{H}+\mathrm{Ar}$ & $1.1 \times 10^{-16}$ & 57 \\
5.3 & $\mathrm{Ar}_{\text {meta }}+\mathrm{N}_{2} \rightarrow \mathrm{N}_{2}(C)+\mathrm{Ar}$ & $3.0 \times 10^{-17}$ & 76 \\
5.4 & $\mathrm{~N}_{2}(A)+\mathrm{H} \rightarrow \mathrm{N}_{2}+\mathrm{H}$ & $5.0 \times 10^{-17}$ & 39 \\
5.5 & $\mathrm{~N}_{2}(A)+\mathrm{H}_{2} \rightarrow \mathrm{N}_{2}+2 \mathrm{H}$ & $2.0 \times 10^{-16}$ & 39 \\
5.6 & $\mathrm{~N}_{2}(A)+\mathrm{NH}_{3} \rightarrow \mathrm{N}_{2}+\mathrm{NH}_{3}$ & $1.6 \times 10^{-16}$ & 39 \\
5.7 & $\mathrm{~N}_{2}(B)+\mathrm{H}_{2} \rightarrow \mathrm{N}_{2}(A)+\mathrm{H}_{2}$ & $2.5 \times 10^{-17}$ & 39 \\
5.8 & $\mathrm{~N}_{2}(a)+\mathrm{H} \rightarrow \mathrm{N}_{2}+\mathrm{H}$ & $1.5 \times 10^{-17}$ & 39 \\
5.9 & $\mathrm{~N}_{2}(a)+\mathrm{H}_{2} \rightarrow \mathrm{N}_{2}+2 \mathrm{H}$ & $2.6 \times 10^{-17}$ & 39 \\
5.10 & $\mathrm{~N}(D)+\mathrm{H}_{2} \rightarrow \mathrm{NH}+\mathrm{H}$ & $2.3 \times 10^{-18}$ & 39 \\
5.11 & $\mathrm{~N}(D)+\mathrm{NH}_{3} \rightarrow \mathrm{NH}+\mathrm{NH}$ & $1.1 \times 10^{-16}$ & 39 \\
5.12 & $\mathrm{~N}(P)+\mathrm{H}_{2} \rightarrow \mathrm{NH}+\mathrm{H}$ & $2.5 \times 10^{-20}$ & 39
\end{tabular}

TABLE IX. Reaction set with rate coefficients $K$ for reactions $k$ involving excited species.

can be reduced to 6 reactions for Ar, 23 reactions for $\mathrm{N}_{2}$ and $\mathrm{N}$, and 12 mixed reactions shown in Tables VII, VIII, and IX, respectively. These reactions are the dominant ones and they are sufficient to calculate the metastable densities $n_{\mathrm{X}_{\text {meta }}}$ with $\mathrm{X}=\mathrm{Ar}, \mathrm{N}_{2}$, and $\mathrm{N}$ with sufficient accuracy. For metastable Ar and $\mathrm{N}_{2}$ the wall loss rate coefficient $K_{w}$ is used ${ }^{77,79}$ :

$$
\frac{1}{K_{w}}=\frac{\Lambda^{2}}{D}+\frac{V}{A} \frac{2(2-\beta)}{\beta} \frac{1}{v}
$$

$\left(\Lambda=l_{e l} / \pi\right.$ - diffusion length, $D$ - diffusion constant ${ }^{54}, V / A=l_{e l} / 2$ - volume-to-surface ratio for wall loss, $\beta$ - surface loss probability of the considered species, value are listed in Tables VII and VIII). Eq. 8 was derived for neutrals diffusing through the plasma volume and are lost on the wall ${ }^{79}$. $v$ is calculated by the mean velocity: $v=\sqrt{8 k_{B} T / \pi M}$ with $T$ and $M$ being the temperature and mass of the considered species, respectively. For the wall loss rate coefficients of the metastables $\mathrm{N}(D)$ and $\mathrm{N}(P)$ Thorsteinsson and Gudmundsson ${ }^{77}$ used the same values as for $\mathrm{N}$ in the ground state. Therefore, for $\mathrm{N}(D)$ and $\mathrm{N}(P)$ the same value as for $\mathrm{N}$ in the ground state is used here, too. The latter will be determined in Sec. IV (see Table VIII).

\section{WALL LOSS TIMES OF RADICALS DETERMINED FROM AFTERGLOW MEASUREMENTS}

For low-pressure plasmas the main loss channel of radicals is the loss to the wall ${ }^{23,80-82}$ which can be expressed by a certain wall loss time $t_{\text {wrad }}$. The radical wall loss time $t_{\text {wrad }}$ is usually described by a diffusive part and a surface loss part ${ }^{23,68}$. Hence, it is a function of the diffusion constant $D_{r a d}$, the discharge geometry, the radical temperature $T_{r a d}$, and the surface loss probability $\beta_{\text {rad }}$ (see Eq. 8). In our experiment the geometry of the plasma chamber does not exhibit a simple cylindrical geometry and the plasma-surrounding walls consist of different materials which have different $\beta_{\text {rad }}$. Furthermore, the radical temperature 
is a priori not known since radicals are mainly produced by dissociation which is accompanied by a release of potential Franck-Condon energy ${ }^{44}$ and $T_{r a d}$ can, therefore, exceed the gas temperature considerably. $\beta_{\text {rad }}$ is a function of the radical species ${ }^{49,83}$, the surface material $^{50,81,83,84}$, but most likely also a function of the surface condition ${ }^{85}$ (for example, substrate temperature and roughness) and even the plasma parameters ${ }^{81,86}$ (for example, ion flux). Values of $\beta_{\text {rad }}$ for one radical species and the same surface material can vary up to an order of magnitude in the literature (compare values in Refs. ${ }^{50,80,81,86}$ or in Refs. ${ }^{49,87}$ ). Furthermore it has to be kept in mind that $\beta_{\mathrm{N}}$ values are in general determined from measured data on the basis of a diffusion model which describes the transport of the radical particles to the chamber walls. This evaluation procedure depends to a large extent on assumptions on the relevant geometry of the plasma chamber and on the assumption about the radical temperature. Summarizing, describing $t_{\text {wrad }}$ by a model is not possible due to unknown input parameters. In the present work, another approach is realized: $t_{\text {wrad }}$ is measured directly for selected plasma conditions. This is done by monitoring the radical density in the temporal afterglow of the plasma. In this phase the production process of radicals (electron-induced dissociation) is terminated within microseconds ${ }^{88}$ and the only important loss process is the loss to the wall ${ }^{50,80,81,86}$. The relative radical densities for the radical species $\mathrm{H}, \mathrm{N}, \mathrm{NH}$, and $\mathrm{NH}_{2}$ are measured by ionization threshold mass spectrometry in a pulsed plasma (see Sec. IIF).

The aim is to determine the wall loss time $t_{\text {wrad }}$ of the radical particles in the $\mathrm{H}_{2}-\mathrm{N}_{2}$ - $\mathrm{Ar}$ plasma at $1.5 \mathrm{~Pa}$. However, at $1.5 \mathrm{~Pa} \mathrm{H}_{2}-\mathrm{N}_{2}$-Ar plasmas do not ignite reliably so that an operation in a pulsed mode for measuring the decay time is not possible. Only at higher pressures equal to or greater than $3.0 \mathrm{~Pa} \mathrm{H}_{2}-\mathrm{N}_{2}$ - $\mathrm{Ar}$ plasmas ignite reliably for all studied $\mathrm{N}_{2}$ partial pressure fraction. However, when using deuterium instead of protium, i.e. $\mathrm{D}_{2}-\mathrm{N}_{2}$ Ar, ignites reliably even at $1.5 \mathrm{~Pa}$ plasma. Therefore, a $\mathrm{D}_{2}-\mathrm{N}_{2}$-Ar plasma is studied. The transferability of the results of $\mathrm{D}_{2}-\mathrm{N}_{2}$-Ar to the $\mathrm{H}_{2}-\mathrm{N}_{2}$-Ar plasma is investigated at $3.0 \mathrm{~Pa}$ for nearly identical plasma conditions. In addition, measurements in a pure $\mathrm{H}_{2}$ and $\mathrm{D}_{2}$ plasma are performed. For the mixed $\mathrm{D}_{2}-\mathrm{N}_{2}$-Ar plasma $t_{\text {wrad }}$ was measured for only two $\mathrm{N}_{2}$ partial pressure fractions at $1.5 \mathrm{~Pa}$ in the pulsed plasma mode as the ITMS measurements are elaborate and time consuming.

Wall loss times $t_{\text {wrad }}$ are determined from the temporal decay curves in the afterglow of the plasma. For the plasma conditions $p=1.5 \mathrm{~Pa} f_{\mathrm{N}_{2}}=21 \%, r f$ power $200 \mathrm{~W}, t_{\text {on }}=3 \mathrm{~ms}$, and $t_{\text {off }}=10 \mathrm{~ms}$ the measured signals of the relative densities of $\mathrm{D}, \mathrm{N}$, and ND in the pulsed plasma are shown in Fig. 1 as a function of time $t$. The time axis is chosen such that at $t=0$ the power-off phase begins. The power-on $\left(P_{o n}\right)$ phase $\left(t_{o n}=3 \mathrm{~ms}\right)$ is characterized by a signal increase within the first $0.3 \mathrm{~ms}$ of the pulse followed by a region between -2 and $0 \mathrm{~ms}$ where the signal is maximal and constant. The $P_{\text {off }}$ phase is characterized by a strong decrease of the signal. The signal drop in the first $1 \mathrm{~ms}$ is substantially faster than for $t \gtrsim 1 \mathrm{~ms}$. For large $t$ in the $P_{\text {off }}$ phase the signal exhibits a small background. The signal in the $P_{\text {off }}$ phase can be well described by a function which is the sum of two exponentials and a constant background:

$$
y=C_{1} e^{-t / t_{\text {wad }}}+C_{2} e^{-t / t_{\text {wad }, 2}}+y_{0} .
$$




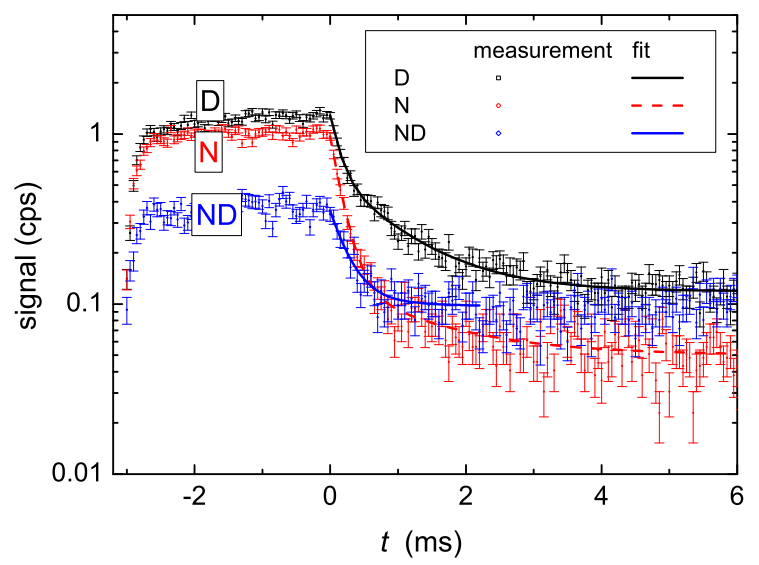

FIG. 1. Plasma monitor signal on mass channels 2, 14, and $16 \mathrm{amu} / \mathrm{e}$ at electron energies of 15, 18 , and $16 \mathrm{eV}$, respectively, in a pulsed $\mathrm{D}_{2}-\mathrm{N}_{2}-\mathrm{Ar}$ plasma for the plasma conditions $p=1.5 \mathrm{~Pa}$, $f_{\mathrm{N}_{2}}=21 \%, P_{r f}=200 \mathrm{~W}, t_{o n}=3 \mathrm{~ms}$, and $t_{\text {off }}=10 \mathrm{~ms}$.

\begin{tabular}{cccccc|cccc}
$p$ & $f_{\mathrm{H}_{2}}$ & $f_{\mathrm{D}_{2}}$ & $f_{\mathrm{N}_{2}}$ & $f_{\mathrm{Ar}}$ & $f_{\mathrm{NH}_{3}}$ & $t_{w \mathrm{H} / \mathrm{D}}$ & $t_{w \mathrm{~N}}$ & $t_{w \mathrm{NH} / \mathrm{ND}}$ & $t_{w \mathrm{NH}_{2}}$ \\
$(\mathrm{~Pa})$ & $(\%)$ & $(\%)$ & $(\%)$ & $(\%)$ & $(\%)$ & \multicolumn{4}{|c}{$(\mathrm{ms})$} \\
\hline 3.0 & 69 & 0 & 21 & 1.5 & 8.5 & 0.33 & 0.30 & 0.64 & 0.40 \\
3.0 & 0 & $67 *$ & $21 *$ & $1.8 *$ & $10.2 *$ & 0.28 & 0.34 & 0.39 & \\
1.5 & 0 & 67 & 21 & 1.8 & 10.2 & 0.14 & 0.17 & 0.27 & \\
1.5 & 0 & 92 & 3.3 & 1.5 & 3.2 & 0.17 & 0.28 & 0.31 &
\end{tabular}

TABLE X. Measurement results of the wall loss time $t_{w r a d}$ of radicals from plasma monitor afterglow measurements for various pressures $p$ and partial pressure fractions $f_{j} \cdot \mathrm{H}_{2}-\mathrm{N}_{2}$ - $\mathrm{Ar}$ and $\mathrm{D}_{2}-\mathrm{N}_{2}$-Ar plasmas are studied at $3.0 \mathrm{~Pa}$ (Power $300 \mathrm{~W}, t_{\text {on }}=10 \mathrm{~ms}, t_{\text {off }}=20 \mathrm{~ms}$ ) and $1.5 \mathrm{~Pa}$ (power $200 \mathrm{~W}, t_{o n}=3 \mathrm{~ms}, t_{o f f}=10 \mathrm{~ms}$ ). $*$ - extrapolated values from $1.5 \mathrm{~Pa}$ measurements since same gas flows were used.

$C_{1}, C_{2}$, and $y_{0}$ are fitting constants, $t_{w r a d, 2}$ is the time constant of the slowly decaying part. The fit curve is included in Fig. 1. For all studied mixed plasmas Eq. 9 is used for fitting the measured decay curves. The wall loss times obtained in this way for all studied plasma conditions can be found in Table X. The wall loss times are in the range between 0.1 and $0.6 \mathrm{~ms}$. If the pressure is decreased from 3.0 to $1.5 \mathrm{~Pa}$ the wall loss times $t_{w \mathrm{D}}$ and $t_{w \mathrm{~N}}$ also decrease by a factor of 2 for all studied $f_{\mathrm{N}_{2}}$. At a constant pressure of $1.5 \mathrm{~Pa}$ but decreasing nitrogen partial pressure fraction from $f_{\mathrm{N}_{2}}=21 \%$ to $f_{\mathrm{N}_{2}}=3.3 \%, t_{w \mathrm{~N}}$ decreases by a factor of 1.6. For ND $t_{w \mathrm{ND}}$ decreases moderately with decreasing $p$, independently from the studied $f_{\mathrm{N}_{2}}$.

For $\mathrm{ND}_{2}$ the wall loss time $t_{w \mathrm{ND}_{2}}$ could not be measured. For a mass spectrometer cathode voltage of $14 \mathrm{eV}$ both $\mathrm{ND}_{2}$ and $\mathrm{H}_{2} \mathrm{O}$ produce ions leading to a signal on mass channel $18 \mathrm{amu} / \mathrm{e}$. It is observed that the signal on this mass channel does not vary in a pulsed plasma in the investigated time range of $10 \mathrm{~ms}$. Therefore, most likely the measured 


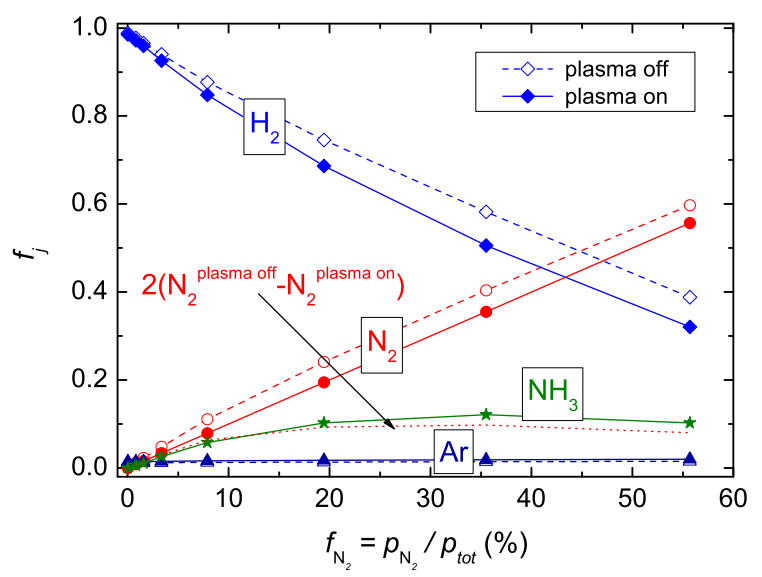

FIG. 2. partial pressure fractions $f_{j}$ of $j=\mathrm{H}_{2}, \mathrm{~N}_{2}, \mathrm{Ar}$, and $\mathrm{NH}_{3}$ measured with the molecularbeam mass spectrometer as a function of $f_{\mathrm{N}_{2}}=f_{\mathrm{N}_{2}}\left(P_{o n}\right)$ for a total pressure of $1.5 \mathrm{~Pa}$ and an $r f$ power of $200 \mathrm{~W}$ during plasma-off (open symbols) and plasma-on phase (solid symbols).

signal on mass channel $18 \mathrm{amu} / \mathrm{e}$ originates dominantly from $\mathrm{H}_{2} \mathrm{O}$ from the residual gas of the PM chamber.

The wall loss times of $\mathrm{H}$ and $\mathrm{D}$ in the $\mathrm{H}_{2}-\mathrm{N}_{2}$ - Ar and $\mathrm{D}_{2}-\mathrm{N}_{2}$-Ar plasma at 3.0 Pa differ only slightly. We assume that the wall loss time is the same for protonated and deuterated species, i.e., shows no isotope effect. Therefore, the wall loss times measured for the deuterated case will in the following also be applied for the $\mathrm{H}_{2}-\mathrm{N}_{2}$-Ar plasma.

The wall loss times of the radicals $\mathrm{H}, \mathrm{N}, \mathrm{NH}$, and $\mathrm{NH}_{2}$ used in the model are the mean values of the two measurements for a pressure of $1.5 \mathrm{~Pa}$, i.e., mean values of the two last lines in Table $\mathrm{X}$ for each species. In detail, these are $t_{w \mathrm{H}}=0.16 \mathrm{~ms}$ for $\mathrm{H}, t_{w \mathrm{~N}}=0.23 \mathrm{~ms}$ for $\mathrm{N}$, and $t_{w \mathrm{NH}}=0.29 \mathrm{~ms}$ for atomic hydrogen. Since for $\mathrm{NH}_{2}$ no experimental data could be obtained, the value of $\mathrm{NH}$, i.e., $t_{w \mathrm{NH}_{2}}=0.29 \mathrm{~ms}$ is used assuming they behave similarly. It is assumed that these wall loss times are valid as model input parameters of the studied $\mathrm{H}_{2}$ $\mathrm{N}_{2}$-Ar plasma for a total pressure of $1.5 \mathrm{~Pa}$ (see Sec. V) for the studied $\mathrm{N}_{2}$ partial pressure fractions of 3.3 and $21 \%$ (as measured, see Table X) and are used as approximation for all other considered $\mathrm{N}_{2}$ partial pressure fractions. We want to note here that calculating $t_{\text {wrad }}$ with $\beta_{\text {rad }}$ values taken from the literature ${ }^{7}$ would lead to significantly different results of the rate equation model and, hence, different radical densities which differ up to two orders of magnitude from the values for our case. For a detailed discussion of the discrepancy of $\beta_{\text {rad }}$ between our and other groups, see Refs. ${ }^{43,44}$. 


\section{RESULTS}

\section{A. Partial pressures}

The partial pressure fractions $f_{j}$ determined with the MBMS before and during plasma operation are shown in Fig. 2. As can be seen in Fig. 2, the gas composition during the plasma-on phase differs slightly from that during the plasma-off phase. In particular, $f_{\mathrm{N}_{2}}$ decreases during plasma operation. The gas composition is plotted against $f_{\mathrm{N}_{2}}=f_{\mathrm{N}_{2}}\left(P_{\text {on }}\right)$ because the rate equation model calculates with $f_{j}$ of the $P_{\text {on }}$ phase. The $\mathrm{N}_{2}$ partial pressure fraction is varied and the investigated values of $f_{\mathrm{N}_{2}}$ are $0.02,0.8,1.6,3.4,7.9,20,36$ and $56 \%$. The lowest $f_{\mathrm{N}_{2}}$ for zero input of $\mathrm{N}_{2}$ is 0.02 since a tiny amount of nitrogen is also present in the pure $\mathrm{H}_{2}$-Ar plasma. This small nitrogen partial pressure fraction is probably due to $\mathrm{N}_{2}$ release from the chamber walls during plasma operation. For simplicity, this will in the following be called $f_{\mathrm{N}_{2}}=0 \%$.

Despite constant gas supply, $f_{\mathrm{Ar}}\left(P_{\text {off }}\right)$ increases slightly from $1.2 \%\left(f_{\mathrm{N}_{2}}=0 \%\right)$ to $1.5 \%$ $\left(f_{\mathrm{N}_{2}}=56 \%\right)$ which is attributed to the change in the pumping speed by changing the gas mixture (from $j=\mathrm{H}_{2}$ with mass $M=2 \mathrm{amu}$ to $\mathrm{N}_{2}$ with $28 \mathrm{amu}$ ). If a gas with particles of high mass is mixed with a gas with low mass, the light and fast particles accelerate the heavy particles, so that the gas of heavy particles is pumped faster ${ }^{89}$. At plasma ignition the total pressure of $p=1.5 \mathrm{~Pa}$ decreases at most by $4 \%$ for $\mathrm{N}_{2}$ partial pressure fractions of $f_{\mathrm{N}_{2}}>5 \%$. For lower $\mathrm{N}_{2}$ partial pressure fractions $p$ remains constant within the measurement accuracy of $\pm 2 \%$ during plasma ignition.

\section{B. Ammonia}

In addition to the three stable gas species $\mathrm{H}_{2}, \mathrm{~N}_{2}$, and $\mathrm{Ar}$ originating from the input gas flow, the fourth species ammonia $\left(\mathrm{NH}_{3}\right)$ appears during plasma operation. Ammonia has a higher partial pressure fraction than Ar, but a lower partial pressure fraction than $\mathrm{N}_{2}$. At $f_{\mathrm{N}_{2}}=36 \% f_{\mathrm{NH}_{3}}$ has a maximum with a partial pressure fraction of $12.1 \%$. The $f_{\mathrm{H}_{2}}$ ratio between $P_{\text {on }}$ and $P_{\text {off }}$ decreases with increasing $f_{\mathrm{N}_{2}}$ from $f_{\mathrm{H}_{2}}\left(P_{o n}\right) / f_{\mathrm{H}_{2}}\left(P_{\text {off }}\right)=1$ to 0.83. The $f_{\mathrm{N}_{2}}$ ratio between $P_{\text {on }}$ and $P_{\text {off }}$ is between $f_{\mathrm{N}_{2}}\left(P_{o n}\right) / f_{\mathrm{N}_{2}}\left(P_{\text {off }}\right)=0.68$ and 0.93 . With respect to the nitrogen balance we can state the following: the nitrogen atoms which appear as $\mathrm{NH}_{3}$ are compared with the missing nitrogen atoms of the $\mathrm{N}_{2}$ gas input. The latter corresponds to twice the difference of the $\mathrm{N}_{2}$ density between the plasma-off and plasma-on phase. This missing nitrogen partial pressure fraction of $2 \times\left(f_{\mathrm{N}_{2}}\left(P_{\text {off }}\right)-f_{\mathrm{N}_{2}}\left(P_{\text {on }}\right)\right)$ is shown in Fig. 2 and matches $f_{\mathrm{NH}_{3}}$ very well. This agreement shows that the missing $\mathrm{N}_{2}$ during $P_{\text {on }}$ appears as $\mathrm{NH}_{3}$.

In the following the production of ammonia is shortly discussed. One pathway that could lead to ammonia production are gas phase reactions. Calculating the $\mathrm{NH}_{3}$ density with the rate equation model (see Sec. III) taking into account only volume reactions producing $\mathrm{NH}_{3}$ shows that the calculated $\mathrm{NH}_{3}$ density is in the whole $f_{\mathrm{N}_{2}}$ range 4 orders of magnitude below the measured $\mathrm{NH}_{3}$ density of Fig. 2. That means that volume reactions producing $\mathrm{NH}_{3}$ play only a negligible role. Therefore, $\mathrm{NH}_{3}$ must be produced on the plasma surrounding 
walls. It is generally accepted that one mechanism for ammonia production is based on the adsorption of atomic hydrogen and nitrogen on surrounding surfaces followed by gradual recombination of adsorbed atomic nitrogen $\mathrm{N}(s)$ and hydrogen $\mathrm{H}(s)$ to $\mathrm{NH}_{3}$ with $\mathrm{NH}(s)$ and $\mathrm{NH}_{2}(s)$ as intermediate reaction products. For a detailed model see Refs. ${ }^{3,30,38}$. A quantitative description of $\mathrm{NH}_{3}$ production is not attempted in the present work since this surface reaction model would require the input of several unknown parameters. For example, in the $\mathrm{H}_{2}-\mathrm{N}_{2}$ mixture it is unclear to what extent $\mathrm{H}$ returns as $\mathrm{H}_{2}$ and as $\mathrm{NH}_{3}$ from the wall, i.e., the partial surface recombination probabilities of $\mathrm{H}$ recombining with adsorbed species at the wall are not known. In the following the measured $\mathrm{NH}_{3}$ density is taken as an input parameter in the model because the used model does not account for surface reactions for the production of $\mathrm{NH}_{3}$.

With respect to the $f_{\mathrm{NH}_{3}}$ we would like to add the following note summarizing some additional experimental results: The maximum of $f_{\mathrm{NH}_{3}}$ at $f_{\mathrm{N}_{2}}=36 \%$ and the $f_{\mathrm{NH}_{3}}$ dependence as a function of $f_{\mathrm{N}_{2}}$ are also observed for an $\mathrm{H}_{2}-\mathrm{N}_{2}$ - Ar plasma with 3.0 $\mathrm{Pa}$ and for a $\mathrm{D}_{2}-\mathrm{N}_{2}$-Ar plasma with 1.5 Pa for otherwise identical plasma conditions. The production of $\mathrm{NH}_{3}$, therefore, seems to be not significantly influenced by a pressure increase by a factor of 2 or an exchange of $\mathrm{H}_{2}$ with $\mathrm{D}_{2}$. For a power variation from 100 to $600 \mathrm{~W}(p=1.5 \mathrm{~Pa}$, $\mathrm{H}_{2}-\mathrm{N}_{2}$-Ar, $f_{\mathrm{N}_{2}}=3.4 \%, f_{\mathrm{Ar}}=1.5 \%$ ) a non-monotonic increase of $f_{\mathrm{NH}_{3}}$ is observed. In this power variation, $T_{e}$ stays approximately constant, $n_{e}$ increases linearly from $2.8 \times 10^{15} \mathrm{~m}^{-3}$ to $3.2 \times 10^{16} \mathrm{~m}^{-3}$ and the measured hydrogen dissociation degree $n_{\mathrm{H}} / n_{\mathrm{H}_{2}}$ also increases linearly from 0.0023 to 0.024 with increasing power. In an earlier publication it was shown that $n_{\mathrm{H}} / n_{\mathrm{H}_{2}}$ is proportional to $n_{e}{ }^{23}$ (see also Sec. V D) and this trend is here confirmed. Furthermore, from the model we find that also the atomic nitrogen density increases linearly with increasing $n_{e}$ and, hence, increasing power. However, the measured $f_{\mathrm{NH}_{3}}$ increases non-monotonically. From 100 to $300 \mathrm{~W} f_{\mathrm{NH}_{3}}$ increases from 1.7 to $3.1 \%$. From 300 to $600 \mathrm{~W} f_{\mathrm{NH}_{3}}$ increases from 3.1 to $3.9 \%$. In summary, the relatively high ammonia fraction of several percent was proven for a broad variation of plasma conditions.

Chen et al. ${ }^{32}$ examined an inductively coupled plasma at $1 \mathrm{~Pa}$ and $400 \mathrm{~W}$ rf power. They measured the $\mathrm{NH}_{3}$ density with a quadrupole mass spectrometer for plasma conditions comparable with the present study. They studied $n_{\mathrm{NH}_{3}}$ in a remote area (chamber material: stainless steel) connected with the plasma chamber by a $5 \mathrm{~mm}$ orifice. A $f_{\mathrm{N}_{2}}$ variation showed that the $\mathrm{NH}_{3}$ density exhibited a maximum of $n_{\mathrm{NH}_{3}}=2 \times 10^{19} \mathrm{~m}^{-3}$ for $f_{\mathrm{N}_{2}}=40 \%$. This $n_{\mathrm{NH}_{3}}$ corresponds to a $\mathrm{NH}_{3}$ partial pressure fraction of $8 \%$ of the total gas density for which a gas temperature $T_{g}=300 \mathrm{~K}$ is assumed. Since $\mathrm{NH}_{3}$ is produced on the chamber wall, consequently, the $\mathrm{NH}_{3}$ production depends on the surface area of the chamber wall which is different between Chen et al. and the present study. Despite the differences in the design of the plasma chamber resulting in different surface areas between the experiments by Chen et al. and the present work, both the maximum of the $\mathrm{NH}_{3}$ partial pressure fraction as well as the position of the maximum agree surprisingly well with each other (present work: maximum of $f_{\mathrm{NH}_{3}}=12 \%$ for $f_{\mathrm{N}_{2}}=36 \%$ ). 


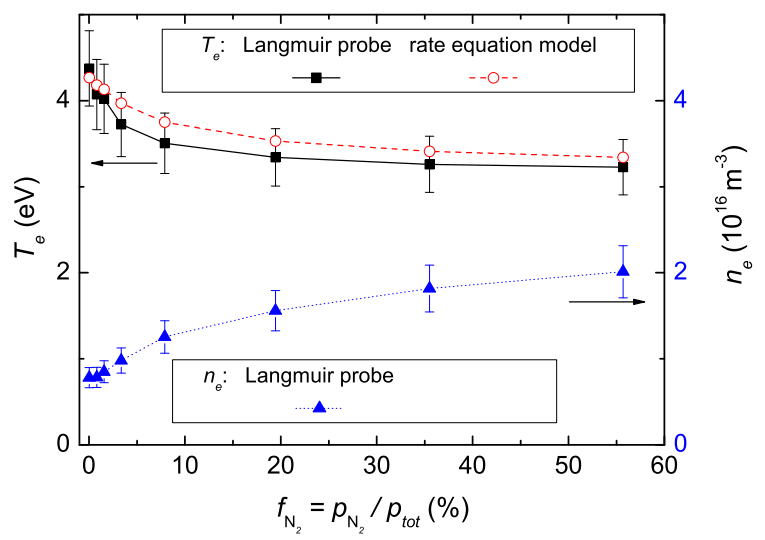

FIG. 3. Measured and modeled electron temperature $T_{e}$ as well as measured electron density $n_{e}$.

\section{Electron temperature and density}

$T_{e}$ is on the one hand experimentally measured with the Langmuir probe and on the other hand determined with the rate equation model. As described in Sec. III in our model $T_{e}$ is fitted to fulfill the quasi-neutrality condition. The measured and fitted electron temperatures are plotted in Fig. 3 as a function of $f_{\mathrm{N}_{2}}$. The measured $T_{e}$ of the hydrogen plasma with $1.2 \%$-Ar partial pressure fraction $\left(f_{\mathrm{N}_{2}}=0 \%\right)$ is $4.4 \mathrm{eV}$. With increasing $\mathrm{N}_{2}$ the measured $T_{e}$ decreases monotonically reaching $3.2 \mathrm{eV}$ for $f_{\mathrm{N}_{2}}=56 \%$. The modeled $T_{e}$ shows the same behavior as the measured $T_{e}$. The calculated values agree with the measured ones within the experimental uncertainty but are systematically at slightly (about $0.2 \mathrm{eV}$ ) higher values. All in all, the rate equation model describes $T_{e}$ very well. In Fig. 3 also the electron density $n_{e}$ is shown which was obtained experimentally by Langmuir probe measurement. $n_{e}$ increases with increasing $f_{\mathrm{N}_{2}}$ monotonically from $0.8 \times 10^{16} \mathrm{~m}^{-3}$ at $f_{\mathrm{N}_{2}}=0 \%$ to $2 \times 10^{16} \mathrm{~m}^{-3}$ at $f_{\mathrm{N}_{2}}=56 \%$.

\section{Radical densities}

The absolute densities of the radical particles are calculated with the rate equation model described in section III. The key input parameters for the rate equation model for calculating $n_{\text {rad }}$ are $f_{j}$ (power-on phase; including $\mathrm{NH}_{3}$ ), $n_{e}$, and $t_{\text {wrad }}$. The results for the calculated radical densities are shown in Fig. 4. The calculated density of atomic hydrogen $n_{\mathrm{H}}$ is in the range of $0.0 \leq f_{\mathrm{N}_{2}} \leq 10 \%$ roughly constant at $2 \times 10^{18} \mathrm{~m}^{-3}$ and decreases slightly with further increasing $f_{\mathrm{N}_{2}}$. The densities of atomic nitrogen in the ground state and in the metastable state $\mathrm{N}(D)$ as well as $n_{\mathrm{NH}}$ and $n_{\mathrm{NH}_{2}}$ increase monotonically. At $f_{\mathrm{N}_{2}}=0.8 \% n_{\mathrm{H}}$ is more than two orders of magnitude higher than the other densities considered here. At $f_{\mathrm{N}_{2}}>15 \% n_{\mathrm{H}}, n_{\mathrm{NH}}$, and $n_{\mathrm{NH}_{2}}$ show comparable densities while those of $n_{\mathrm{N}}$ and $n_{\mathrm{N}(D)}$ are still substantially lower.

In addition to the modeled values, the measured hydrogen density determined by optical 


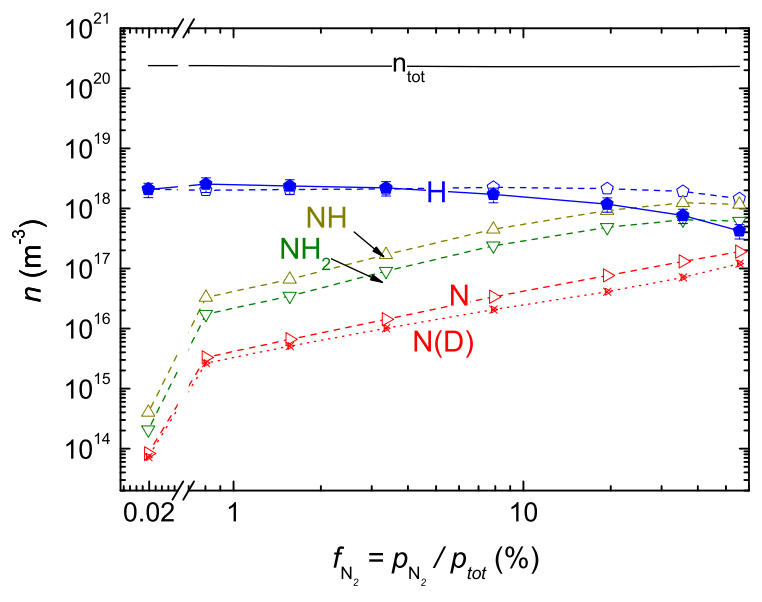

FIG. 4. The calculated densities (open symbols) of the radicals $\mathrm{H}, \mathrm{N}$ (ground state $\mathrm{N}$ and metastable state $\mathrm{N}(D)$ ), $\mathrm{NH}$, and $\mathrm{NH}_{2}$ as a function of $f_{\mathrm{N}_{2}}$ (first value at $f_{\mathrm{N}_{2}}=0.02 \%$ ). In addition, the $\mathrm{H}$ density measured by optical emission spectroscopy and actinometry is shown (solid symbols). For comparison the total density $n_{t o t}$ of the gas mixture is plotted.

\begin{tabular}{l|l|l|l|l} 
Species & Reaction & $k$ & $\begin{array}{l}R_{k} / R_{\text {tot }}\left(f_{\mathrm{N}_{2}}=0.8 \%\right) \\
(\%)\end{array}$ & $\begin{array}{l}R_{k} / R_{\text {tot }}\left(f_{\mathrm{N}_{2}}=56 \%\right) \\
(\%)\end{array}$ \\
\hline $\mathrm{H}$ & $\mathbf{e}^{-}+\mathbf{H}_{2} \rightarrow 2 \mathbf{H}+\mathbf{e}^{-}$ & 1.1 & 89 & 56 \\
& $\mathrm{e}^{-}+\mathrm{NH}_{3} \rightarrow \mathrm{NH}_{2}+\mathrm{H}+\mathrm{e}^{-}$ & 1.19 & $<10$ & 18 \\
\hline $\mathrm{N}$ & $\mathbf{e}^{-}+\mathbf{N}_{2} \rightarrow \mathbf{N}+\mathbf{N}(D)+\mathbf{e}^{-}$ & 1.6 & 88 & 89 \\
\hline $\mathrm{NH}$ & $\mathbf{e}^{-}+\mathbf{N H}_{3} \rightarrow \mathbf{N H}+\mathbf{H}_{2}+\mathbf{e}^{-}$ & 1.21 & 83 & 84 \\
& $\mathrm{e}^{-}+\mathrm{NH}_{3} \rightarrow \mathrm{NH}+2 \mathrm{H}+\mathrm{e}^{-}$ & 1.20 & 15 & $<10$ \\
\hline $\mathrm{NH}_{2}$ & $\mathbf{e}^{-}+\mathbf{N H}_{3} \rightarrow \mathbf{N H}_{2}+\mathbf{H}+\mathbf{e}^{-}$ & 1.19 & 91 & 79
\end{tabular}

TABLE XI. Most important reactions $k$ for the production of the radical species $\mathrm{H}, \mathrm{N}, \mathrm{NH}$, and $\mathrm{NH}_{2}$. In addition, the relative reaction rates $R_{k} / R_{\text {tot }}$ are presented for $f_{\mathrm{N}_{2}}=0.8 \%$ and $f_{\mathrm{N}_{2}}=56 \%$. Only reactions with $R_{k} / R_{\text {tot }}>10 \%$ are shown.

emission spectroscopy (OES) and actinometry is shown in Fig. 4 (see Sec. II C). Densities of nitrogen and ammonia could not be measured with OES since no suitable emission lines were observed. For low $\mathrm{N}_{2}$ partial pressure fraction $\left(f_{\mathrm{N}_{2}}<7.9 \%\right)$ the measured $n_{\mathrm{H}}$ agrees with the calculated values within the experimental uncertainty. With increasing $f_{\mathrm{N}_{2}}\left(f_{\mathrm{N}_{2}}>7.9 \%\right)$ the measured $n_{\mathrm{H}}$ decreases considerably whereas the calculated density decreases slightly resulting in a significant deviation between model and experiment. The deviation in $n_{\mathrm{H}}$ between model and experiment is attributed to the dependence of the $\mathrm{H}$ wall loss time, i.e., the surface loss probability $\beta_{\mathrm{H}}$ on $f_{\mathrm{N}_{2}}$ (for details, see Ref. ${ }^{54}$ ), which is not taken into account in the model. With increasing $\mathrm{N}_{2}$ partial pressure fraction $\beta_{\mathrm{H}}$ increases and thus $n_{\mathrm{H}}$ decreases. The increase of $\beta_{\mathrm{H}}$ with increasing $f_{\mathrm{N}_{2}}$ is attributed to the recombination of $\mathrm{H}$ to $\mathrm{NH}_{3}$ on the surface which occurs in $\mathrm{H}_{2}-\mathrm{N}_{2}$ mixed plasmas in addition to the recombination of $\mathrm{H}$ to $\mathrm{H}_{2}$ (see also Ref. ${ }^{54}$ ). 


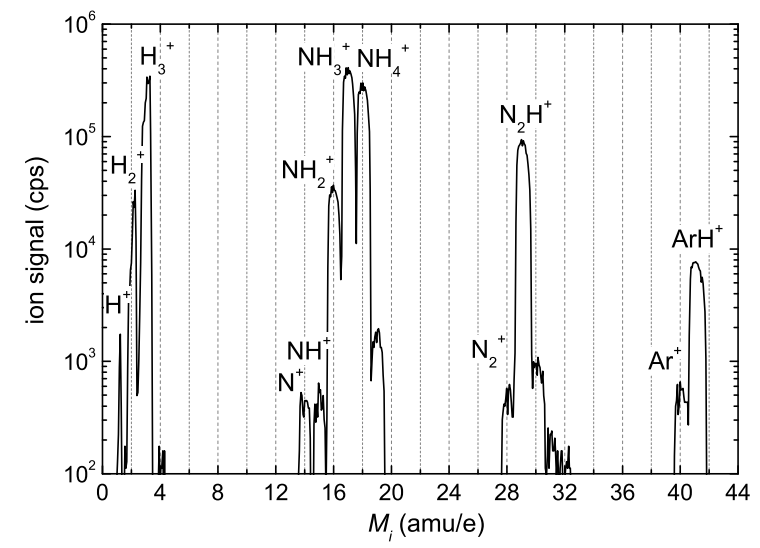

FIG. 5. Ion mass spectrum for $f_{\mathrm{N}_{2}}=3.4 \%$.

In Table XI the most important reactions for the production of the radicals with their corresponding relative reaction rates $R_{k} / R_{\text {tot }}$ are summarized. A reaction rate $R_{k}$ is the product of the educt densities and the rate coefficient $K_{k}$ of a reaction $k$ (for the considered reactions, see Sec. III). The sum of the production reactions of a species is $R_{t o t}=\sum_{k} R_{k}$. In all shown cases the most important reaction for the production of the radical particles is the electron-collision-induced dissociation of the parent molecules. In the examined $\mathrm{H}_{2}-\mathrm{N}_{2}-\mathrm{Ar}$ plasma the electron-collision-induced dissociation contributes more than $50 \%$ to the total production rate $R_{\text {tot }}$. Other reactions with fractions in the range of $10-20 \%$ of $R_{\text {tot }}$ can be found in Table XI. The only significant loss process for the radical particles is the wall loss. The relative loss rate $R_{\text {wrad }} / R_{\text {tot }}$ is greater than $88 \%$ for all considered radicals. Losses through other channels play only a minor role at that pressure of $1.5 \mathrm{~Pa}$. For example, for the loss of ground-state $\mathrm{N}$, reactions 4.9 (electron collision) and 4.14 (collisions with $\mathrm{N}_{2}$ metastables) contribute to $R_{t o t}$ and contribute together at most $10 \%$ to the loss of ground-state $\mathrm{N}$.

We would like to note that the reaction set for the excited species was included in the model to study whether there is an influence of the metastable species on the production of radicals or not. To conclude, $\mathrm{N}(D)$ has a noticeable influence and the $\mathrm{N}(D)$ density is of the order of the ground state $\mathrm{N}$ density. However, other metastables as $\mathrm{N}_{2}(A)$ and $\mathrm{N}(P)$ have only a negligible influence on the dissociation in the studied plasma. The influence of $\mathrm{Ar}_{m}$ is also negligible due to low Ar content.

\section{E. Ion mass spectrum}

Before the experimentally obtained ion densities are presented, first one example of a raw signal is shown in Fig. 5. The ion raw signals cannot be quantitatively compared with each other because they are not calibrated. But, the calibration does not change the signals by orders of magnitude such that rough trends can already be discussed based on the presented 


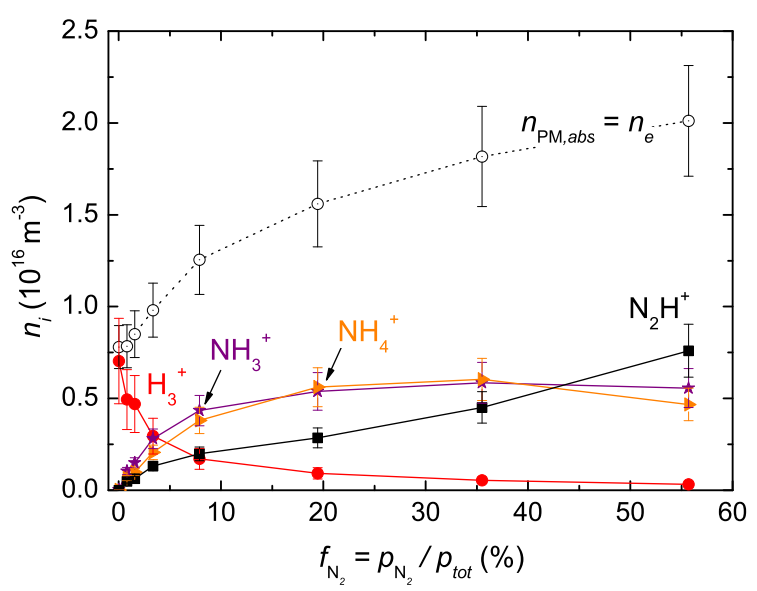

FIG. 6. Measured densities $n_{i}$ of the most abundant ions. The total ion density $n_{\mathrm{PM}, a b s}$ corresponds to the electron density $n_{e}$.

ion mass spectrum. In Fig. 5 the PM raw signal for the ion mass spectrum is shown for a $\mathrm{N}_{2}$ partial pressure fraction of $3.4 \%$. The discriminator voltage $V_{\mathrm{PM}}$ in the plasma monitor is set to the maximum of the ion energy distributions (IED) at $21 \mathrm{~V}$. The maxima of the IEDs of $\mathrm{H}^{+}, \mathrm{H}_{2}^{+}$, and $\mathrm{H}_{3}^{+}$are $2 \mathrm{~V}$ lower at $19 \mathrm{~V}$ than for the other considered ionic species. Therefore, the real maxima for these $\mathrm{H}_{x}^{+}$ions are by a factor of about 3 higher than they appear in Fig. 5 (for details, see Sec. IIE). The highest signals in Fig. 5 originate from the ions $\mathrm{H}_{3}^{+}$(at $\left.3 \mathrm{amu} / \mathrm{e}\right), \mathrm{NH}_{3}^{+}(17 \mathrm{amu} / \mathrm{e}), \mathrm{NH}_{4}^{+}(18 \mathrm{amu} / \mathrm{e})$, and $\mathrm{N}_{2} \mathrm{H}^{+}(29 \mathrm{amu} / \mathrm{e})$. One order of magnitude lower are the signals of the $\mathrm{H}_{2}^{+}(2 \mathrm{amu} / \mathrm{e}), \mathrm{NH}_{2}^{+}(16 \mathrm{amu} / \mathrm{e})$, and $\mathrm{ArH}^{+}(41 \mathrm{amu} / \mathrm{e})$. An additional magnitude lower are the signals of $\mathrm{H}^{+}(1 \mathrm{amu} / \mathrm{e}), \mathrm{N}^{+}$ (14 amu/e), $\mathrm{NH}^{+}(15 \mathrm{amu} / \mathrm{e}), \mathrm{N}_{2}^{+}(28 \mathrm{amu} / \mathrm{e})$, and $\mathrm{Ar}^{+}(40 \mathrm{amu} / \mathrm{e})$. All these ionic species will be discussed in this work. The ion densities will be determined from the signals of the ion mass spectra according to the procedure described in Sec. IIE. Signals on other mass channels are not considered in this work. It should be mentioned that the signals of Fig. 5 occurring at $M_{i}=19 \mathrm{amu} / \mathrm{e}$ and $M_{i}=30 \mathrm{amu} / \mathrm{e}$ are attributed to ${ }^{15} \mathrm{NH}_{4}^{+}$and $\mathrm{N}_{2} \mathrm{H}_{2}^{+}$, respectively. For details, see Ref. ${ }^{54}$.

\section{F. Ion densities of the most abundant ions}

The ions with the highest ion densities in the studied $\mathrm{H}_{2}-\mathrm{N}_{2}$-Ar plasma are shown in Fig. 6. $\mathrm{H}_{3}^{+}$is the dominant ion in the range of $0.0 \leq f_{\mathrm{N}_{2}}<3.4 \%$. In this range the $\mathrm{H}_{3}^{+}$ density decreases with increasing $f_{\mathrm{N}_{2}}$. For $3.4<f_{\mathrm{N}_{2}}<40 \% \mathrm{NH}_{3}^{+}$and $\mathrm{NH}_{4}^{+}$show the highest densities and agree with each other within the experimental uncertainty. Finally, $\mathrm{N}_{2} \mathrm{H}^{+}$is the dominant ion at $f_{\mathrm{N}_{2}}=56 \%$, but $\mathrm{NH}_{3}^{+}$and $\mathrm{NH}_{4}^{+}$have only a slightly lower density. The most striking observation in Fig. 6 is the fact that even at rather low $f_{\mathrm{N}_{2}}(>3.4 \%)$ the dominant ions are $\mathrm{NH}_{3}^{+}$and $\mathrm{NH}_{4}^{+}$. This dominance is at first glance unexpected as these ions do not originate from the dominant background gas species $\mathrm{H}_{2}$, but from $\mathrm{NH}_{3}$. For 


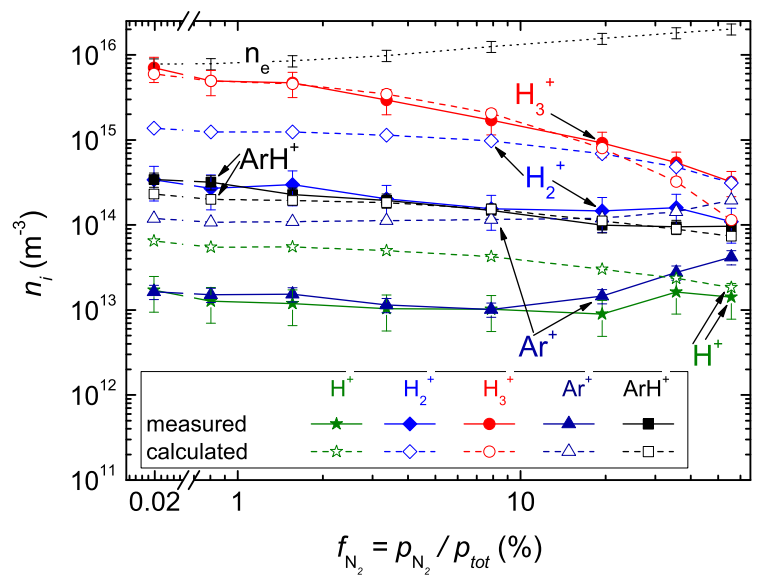

FIG. 7. Measured and calculated ion densities $n_{i}$ of $\mathrm{H}_{x}^{+}(x=1-3), \mathrm{Ar}^{+}$, and $\mathrm{ArH}^{+}$as well as $n_{e}$.

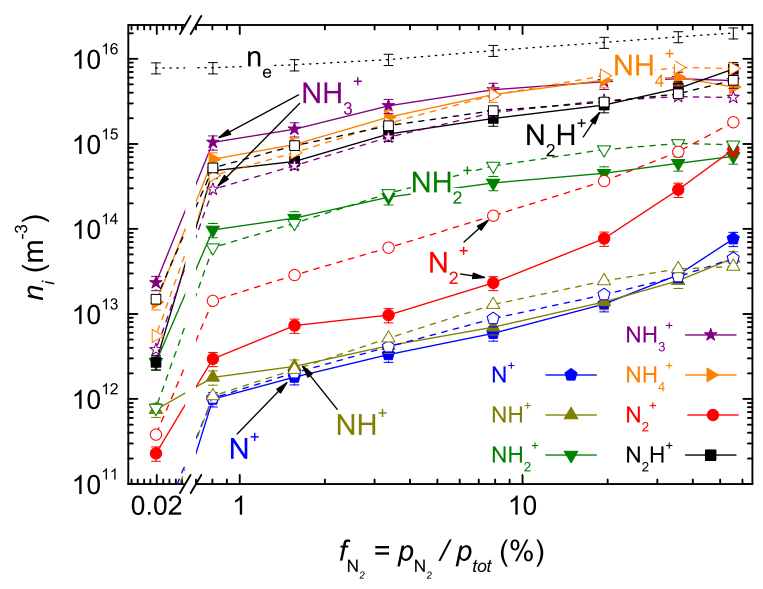

FIG. 8. Measured (solid symbols) and calculated (open symbols) ion densities $n_{i}$ of $\mathrm{NH}_{x}^{+}(x=$ $0-4), \mathrm{N}_{2}^{+}$, and $\mathrm{N}_{2} \mathrm{H}^{+}$as well as $n_{e}$.

$f_{\mathrm{N}_{2}}=3.4 \% \mathrm{NH}_{3}$ has a partial pressure fraction of $f_{\mathrm{NH}_{3}}=2.6 \%$ and it does not exceed $12 \%$ for all considered $f_{\mathrm{N}_{2}}$. Although $f_{\mathrm{N}_{2}}$ is quite low compared with the $\mathrm{H}_{2}$ partial pressure fraction, $\mathrm{NH}_{3}^{+}$and $\mathrm{NH}_{4}^{+}$are the dominant ion species. The electron density $n_{e}$ determined by the Langmuir probe is also shown in Fig. 6. It has to be kept in mind, the total ion density is set equal to the electron density due to the quasi-neutrality (see Sec. IIE).

\section{G. Ion densities - Comparison between experiment and model}

The measured and modeled ion densities are compared in Figs. 7 and 8 as a function of $f_{\mathrm{N}_{2}}$. The ion species containing nitrogen are shown in Fig. 8, while all others are shown in Fig. 7. The densities of the dominant ion species $\mathrm{H}_{3}^{+}$(Fig. 7), $\mathrm{NH}_{3}^{+}, \mathrm{NH}_{4}^{+}$, and $\mathrm{N}_{2} \mathrm{H}^{+}$ 
(Fig. 8), which have densities of more than $1 \times 10^{15} \mathrm{~m}^{-3}$, have already been described in Sec. V F (Fig. 6). Please note that the data in Fig. 6 are shown on a linear scale while data in Figs. 7 and 8 are plotted on double logarithmic scale. The experimental data show the following behaviors: The densities of $\mathrm{H}_{2}^{+}, \mathrm{ArH}^{+}$, and $\mathrm{NH}_{2}^{+}$are predominantly in the range of $10^{14} \mathrm{~m}^{-3}$. While $\mathrm{H}_{2}^{+}$and $\mathrm{ArH}^{+}$(Fig. 7) decrease slightly with increasing $f_{\mathrm{N}_{2}}, \mathrm{NH}_{2}^{+}$(Fig. 8) increases by one order of magnitude in the range of $0.8 \leq f_{\mathrm{N}_{2}} \leq 56 \%$. The density of $\mathrm{N}_{2}^{+}$ is for $f_{\mathrm{N}_{2}}=0.8 \%$ more than 3 orders of magnitude below $n_{e}$, but increases with increasing $f_{\mathrm{N}_{2}}$ by about a factor of 300. Ion species with densities less than $1 \times 10^{14} \mathrm{~m}^{-3}$ are $\mathrm{H}^{+}$, $\mathrm{Ar}^{+}, \mathrm{N}^{+}$, and $\mathrm{NH}^{+} . n_{\mathrm{H}^{+}}$and $n_{\mathrm{Ar}^{+}}$(Fig. 7) vary only slightly with varying $f_{\mathrm{N}_{2}} \cdot n_{\mathrm{N}^{+}}$and $n_{\mathrm{NH}^{+}}$(Fig. 8) increase with $f_{\mathrm{N}_{2}}$ in the range of $0.8 \leq f_{\mathrm{N}_{2}} \leq 56 \%$ by almost two orders of magnitude, but remain only minor contributions to the total ion density. As discussed in Sec. V A a tiny amount of nitrogen $\left(f_{\mathrm{N}_{2}}=0.02 \%\right)$ is also present in the pure $\mathrm{H}_{2}$-Ar plasma (probably released from the wall during plasma operation) and accordingly $\mathrm{N}_{x} \mathrm{H}_{y}^{+}$ions are observed but their densities remain below $3 \times 10^{13} \mathrm{~m}^{-3}$.

In general, the modeled densities are in satisfactory agreement with the experimental data. In the following the similarities and differences between the model results and the experimental data are briefly discussed. We classify the model data into 3 groups: agreement within $20 \%$, within a factor of 2 , and within a factor of 10 .

The calculated ion densities of $n_{\mathrm{H}_{3}^{+}}$in the range of $f_{\mathrm{N}_{2}} \leq 20 \%$ and $n_{\mathrm{ArH}^{+}}$in range of $1.6 \leq f_{\mathrm{N}_{2}} \leq 36 \%$ fit the experimental densities within a maximum deviation of $20 \%$, which means they fit within the experimental accuracy of the measured ion densities. The calculated ion densities of $\mathrm{N}^{+}, \mathrm{NH}^{+}, \mathrm{NH}_{2}^{+}, \mathrm{NH}_{4}^{+}$, and $\mathrm{N}_{2} \mathrm{H}^{+}$agree in the complete range of studied $f_{\mathrm{N}_{2}}$ with the experimental densities within a factor of 2 . The same holds for $\mathrm{NH}_{3}^{+}$ for $f_{\mathrm{N}_{2}}>5 \%$. The calculated densities $n_{\mathrm{N}^{+}}, n_{\mathrm{NH}^{+}}, n_{\mathrm{NH}_{2}^{+}}$, and $n_{\mathrm{N}_{2} \mathrm{H}^{+}}$intersect the measured ones. Calculated ion densities which differ from the experimental densities between a factor of 2 and 10 are the densities of $\mathrm{H}^{+}, \mathrm{H}_{2}^{+}, \mathrm{N}_{2}^{+}$, and $\mathrm{Ar}^{+}$. They all show a similar dependence on $f_{\mathrm{N}_{2}}$ as the measured densities but are all significantly higher. We note that $\mathrm{H}_{2}^{+}, \mathrm{N}_{2}^{+}$, and $\mathrm{Ar}^{+}$are the primary ion species which are produced by direct electron-induced ionization of the background gas species $\mathrm{H}_{2}, \mathrm{~N}_{2}$, and Ar, respectively. However, $\mathrm{H}^{+}$is also a primary ion, but has in contrast to the before-mentioned ion species further important production channels, i.e., electron-induced dissociative ionization from various mother molecules. A possible reason for this deviation will be discussed in the following.

We emphasize again that the applied rate equation model for the $\mathrm{H}_{2}-\mathrm{N}_{2}$-Ar plasma is, on the one hand, zero-dimensional and, therefore, simplified, but on the other hand, very complex with respect to the plasma-chemical reactions. The rate equation model considers 30 different species and more than 150 reactions. Some species densities are strongly dependent on other species densities. Despite this substantial complexity, most of the calculated ion densities match the measured values within a factor of 2 . This agreement is remarkable and probably all that can be anticipated from such a model. The main features, i.e., the dominant ion species for different $\mathrm{N}_{2}$ partial pressure fractions and the dependence of the ion densities and the electron temperature on $f_{\mathrm{N}_{2}}$, are reproduced by the model.

In spite of the acceptable general agreement some quantitative deviations between model and experiment remain. The main quantitative difference is that the densities of the pri- 
mary ions $\mathrm{H}_{2}^{+}, \mathrm{N}_{2}^{+}$and $\mathrm{Ar}^{+}$are clearly overestimated by the model. A sensitivity analysis - similarly as in a former publication ${ }^{23}$ where the model input parameters were varied showed that the plasma cylinder height $l_{e l}$ is a key parameter. A slight improvement in the description of these primary ions can be achieved when $l_{e l}$ was increased. In doing so, the calculated densities of the primary ions decrease with increasing $l_{e l}$ since the rate of ion-molecule collisions in the plasma volume increases. However, to achieve a satisfactory agreement $l_{e l}$ has to be increased by a factor of 3 which is physically not very reasonable. Simulations of the ion densities in less complex plasmas, i.e., $\mathrm{H}_{2}-\mathrm{Ar}$ and $\mathrm{H}_{2}$-He, have shown that the used $l_{e l}$ of $0.06 \mathrm{~m}$ is reasonable for the considered pressure range and describes the measured ion densities well. To investigate this discrepancy between model and experiment for the primary ion densities more accurately, studies with a spatially resolved modeling in the form of a particle-in-cell simulation might give insights, which are not accessible with the present zero-dimensional model.

\section{DISCUSSION}

\section{A. Ion chemistry}

Based on the rate equation model the ion chemistry will be explained in the following. For that purpose the most important reactions for production and loss of the most common ion species are sketched in Fig. 9 for three different $f_{\mathrm{N}_{2}}$. A reaction is denoted as important if this reaction contributes at least $30 \%$ to the total production or total loss rate of the considered ion. For the sake of simplicity the small Ar partial pressure fraction $(\approx 1.5 \%)$ in our plasma is not taken into account in the following discussion because the $\mathrm{Ar}^{+}$and $\mathrm{ArH}^{+}$ion densities are very low (percent range) and have only a small influence on the ion chemistry (see also Sec. VIC).

In the $\mathrm{H}_{2}$ plasma $\left(f_{\mathrm{N}_{2}}=0 \%\right.$, Fig. $\left.9(\mathrm{a})\right) \mathrm{H}_{3}^{+}$is the dominant ion. The primary ion $\mathrm{H}_{2}^{+}$ is produced by the electron-collision-induced reaction $1.3\left(\mathrm{e}^{-}+\mathrm{H}_{2} \rightarrow \mathrm{H}_{2}^{+}+2 \mathrm{e}^{-}\right)$through ionization of the background gas $\mathrm{H}_{2}$. The secondary ion $\mathrm{H}_{3}^{+}$is solely produced by the ionmolecule reaction $2.1\left(\mathrm{H}_{2}^{+}+\mathrm{H}_{2} \rightarrow \mathrm{H}_{3}^{+}+\mathrm{H}\right)$. $\mathrm{H}_{3}^{+}$is mainly lost at the wall. The main loss channel of the primary ion $\mathrm{H}_{2}^{+}$is the conversion into $\mathrm{H}_{3}^{+}$. Thus, the typical reaction chain of ions in an $\mathrm{H}_{2}$ plasma is: electron-impact ionization of the background gas to produce primary ions, conversion of primary ions by ion-molecule reactions with the background gas species to produce secondary ions, and finally the flux of the secondary ions to the wall where they recombine and are lost from the plasma system.

As expected, by addition of $\mathrm{N}_{2}$ to the $\mathrm{H}_{2}$ plasma the ion chemistry becomes more complex. However, in the $\mathrm{H}_{2}-\mathrm{N}_{2}$ plasma with low $\mathrm{N}_{2}$ partial pressure fraction $\left(f_{\mathrm{N}_{2}}=7.9 \%\right.$, Fig. $\left.9(\mathrm{~b})\right)$ the basic reaction chain remains the same as in the $\mathrm{H}_{2}$ plasma. At the beginning of the reaction chain is the ionization of the background gases $\mathrm{H}_{2}, \mathrm{~N}_{2}$, and $\mathrm{NH}_{3}$ for the production of primary ions $\mathrm{H}_{2}^{+}, \mathrm{N}_{2}^{+}$, and $\mathrm{NH}_{3}^{+}$, respectively. The most abundant secondary ions are formed by proton transfer to a primary ion. However, the production of the secondary ions is significantly more complex than in pure $\mathrm{H}_{2}$ plasma. $\mathrm{H}_{3}^{+}$is again generated predominantly from $\mathrm{H}_{2}^{+}$and lost at the wall. But, a small fraction of the $\mathrm{H}_{3}^{+}$ions are converted to $\mathrm{NH}_{4}^{+}$and 
(a)

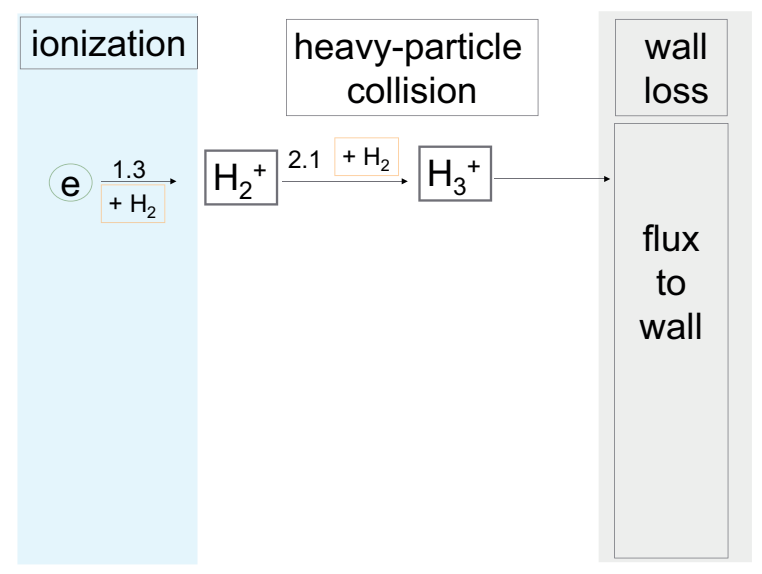

(b)

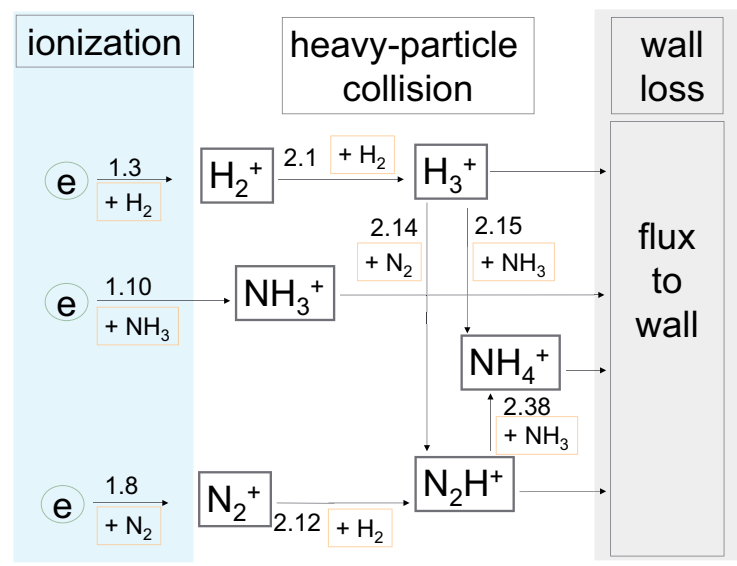

(c)

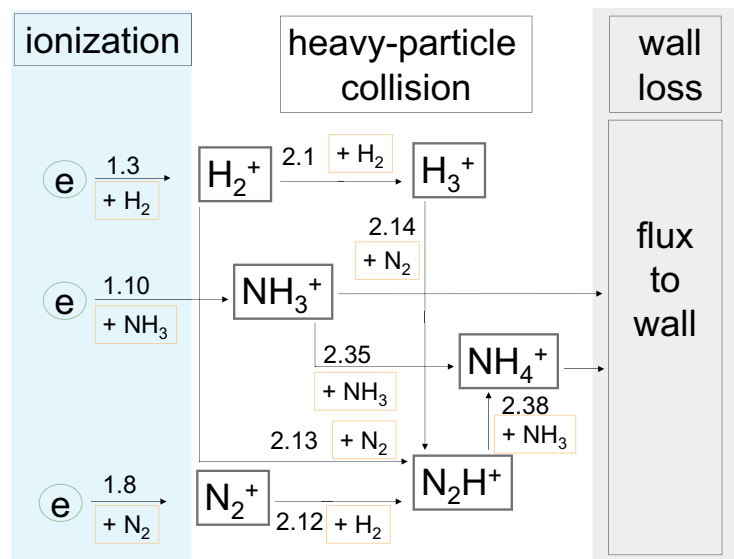

FIG. 9. Production and loss reactions of the most abundant ion species for $f_{\mathrm{N}_{2}}=0 \%$ (a), $f_{\mathrm{N}_{2}}=7.9 \%(\mathrm{~b})$, and $f_{\mathrm{N}_{2}}=56 \%$ (c). The numbers indicate the reactions outlined in Tables II-IV.

$\mathrm{N}_{2} \mathrm{H}^{+}$. Although this is a minor loss channel for $\mathrm{H}_{3}^{+}$it is important for the production of $\mathrm{NH}_{4}^{+}$and $\mathrm{N}_{2} \mathrm{H}^{+}$. They are dominantly produced via reaction $2.15\left(\mathrm{H}_{3}^{+}+\mathrm{NH}_{3} \rightarrow \mathrm{NH}_{4}^{+}+\mathrm{H}_{2}\right)$ and via reaction $2.14\left(\mathrm{H}_{3}^{+}+\mathrm{N}_{2} \rightarrow \mathrm{N}_{2} \mathrm{H}^{+}+\mathrm{H}_{2}\right)$, respectively, since the density of $\mathrm{H}_{3}^{+}$is very high. A priori one could anticipate that $\mathrm{NH}_{4}^{+}$and $\mathrm{N}_{2} \mathrm{H}^{+}$would be produced from $\mathrm{NH}_{3}^{+}$ by ion-molecule reactions via reaction $2.35\left(\mathrm{NH}_{3}^{+}+\mathrm{NH}_{3} \rightarrow \mathrm{NH}_{4}^{+}+\mathrm{NH}_{2}\right)$ and from $\mathrm{N}_{2}^{+}$via reaction $2.12\left(\mathrm{~N}_{2}^{+}+\mathrm{H}_{2} \rightarrow \mathrm{N}_{2} \mathrm{H}^{+}+\mathrm{H}\right)$, respectively, but according to the model, they are 
not. It is interesting to emphasize that the ion-molecule reaction 2.12 is now the dominant loss reaction for $\mathrm{N}_{2}^{+}$and not diffusion to the wall. In contrast, the main loss channel of the most abundant secondary ions $\left(\mathrm{H}_{3}^{+}, \mathrm{NH}_{4}^{+}\right.$, and $\left.\mathrm{N}_{2} \mathrm{H}^{+}\right)$and $\mathrm{NH}_{3}^{+}$is again the loss to the wall.

In contrast to $\mathrm{H}_{2}^{+}$and $\mathrm{N}_{2}^{+}$, the primary ion $\mathrm{NH}_{3}^{+}$reaches the wall mostly without reactive collisions. The rate of reaction 2.35 which is the dominant loss channel of $\mathrm{NH}_{3}^{+}$in the plasma volume is given by the product of the densities of $\mathrm{NH}_{3}^{+}$and $\mathrm{NH}_{3}$ and the corresponding rate coefficient $K_{2.35}$. While the values of $n_{\mathrm{NH}_{3}^{+}}$and $K_{2.35}$ are comparable with the corresponding values of the loss reactions for $\mathrm{H}_{2}^{+}$and $\mathrm{N}_{2}^{+}$, the densities of $\mathrm{H}_{2}$ and $\mathrm{N}_{2}$ are much higher than that of $\mathrm{NH}_{3}$. That is the reason why the rate for the ion-molecule reaction of $\mathrm{NH}_{3}^{+}$with $\mathrm{NH}_{3}$ is much smaller than the dominant loss rates of $\mathrm{H}_{2}^{+}$and $\mathrm{N}_{2}^{+}$. Furthermore, $\mathrm{NH}_{3}^{+}$hardly reacts with $\mathrm{H}_{2}$ (see $K_{2.34}$ in Table IV) and $\mathrm{N}_{2}{ }^{66,90}$. Overall, the sum of the $\mathrm{NH}_{3}^{+}$loss rates of all volume reactions is less than the wall loss rate.

If the $\mathrm{N}_{2}$ partial pressure fraction is increased even more, i.e., $f_{\mathrm{N}_{2}}=56 \%$ (see Fig. 9 (c)) the reaction chain (electron - primary ion - secondary ion - loss to wall) changes insofar that the secondary ions $\mathrm{H}_{3}^{+}$and $\mathrm{N}_{2} \mathrm{H}^{+}$are not mainly lost by recombination at the wall, but by ion-molecule reactions in the plasma volume. These ion-molecule reactions of $\mathrm{H}_{3}^{+}$(reaction 2.14: $\mathrm{H}_{3}^{+}+\mathrm{N}_{2} \rightarrow \mathrm{N}_{2} \mathrm{H}^{+}+\mathrm{H}_{2}$ ) and $\mathrm{N}_{2} \mathrm{H}^{+}$(reaction 2.38: $\mathrm{N}_{2} \mathrm{H}^{+}+\mathrm{NH}_{3} \rightarrow \mathrm{NH}_{4}^{+}+\mathrm{N}_{2}$ ) lead to the production of $\mathrm{NH}_{4}^{+}$. The major loss channel of $\mathrm{NH}_{4}^{+}$is the loss to the wall. Due to the high $\mathrm{N}_{2}$ density, $\mathrm{H}_{2}^{+}$is mainly transformed into $\mathrm{N}_{2} \mathrm{H}^{+}$(reaction 2.13: $\mathrm{H}_{2}^{+}+\mathrm{N}_{2} \rightarrow \mathrm{N}_{2} \mathrm{H}^{+}+\mathrm{H}$ ). However, reaction 2.13 contributes only to a minor part to the total production of $\mathrm{N}_{2} \mathrm{H}^{+}$. $\mathrm{N}_{2} \mathrm{H}^{+}$is predominantly produced by $\mathrm{N}_{2}^{+}$via reaction $2.12\left(\mathrm{~N}_{2}^{+}+\mathrm{H}_{2} \rightarrow \mathrm{N}_{2} \mathrm{H}^{+}+\mathrm{H}\right)$. Also for $f_{\mathrm{N}_{2}}=56 \%, \mathrm{NH}_{3}^{+}$is mainly lost by recombination at the wall. A smaller contribution to the loss of $\mathrm{NH}_{3}^{+}$provides reaction $2.35\left(\mathrm{NH}_{3}^{+}+\mathrm{NH}_{3} \rightarrow \mathrm{NH}_{4}^{+}+\mathrm{NH}_{2}\right)$.

The fact that the ion densities of $\mathrm{NH}_{3}^{+}$and $\mathrm{NH}_{4}^{+}$are larger than that of $\mathrm{H}_{3}^{+}$and $\mathrm{N}_{2} \mathrm{H}^{+}$ over a wide range of $f_{\mathrm{N}_{2}}$ can also be explained with the proton affinities $E_{p a}$. The values are for $\mathrm{H}_{2} E_{p a}=4.37 \mathrm{eV}$ (taken from Ref. ${ }^{91}$; corresponding ion $\left.\mathrm{H}_{3}^{+}\right), \mathrm{N}_{2} 5.12 \mathrm{eV}\left(\mathrm{N}_{2} \mathrm{H}^{+}\right)$, $\mathrm{NH}_{2} 8.01 \mathrm{eV}\left(\mathrm{NH}_{3}^{+}\right)$, and $\mathrm{NH}_{3} 8.86 \mathrm{eV}\left(\mathrm{NH}_{4}^{+}\right)$. The sequence of proton affinities favors the production of $\mathrm{NH}_{3}^{+}$and $\mathrm{NH}_{4}^{+}$against $\mathrm{H}_{3}^{+}$and $\mathrm{N}_{2} \mathrm{H}^{+}$.

\section{B. Discussion of the calculated radical densities}

Because the radical densities were - with the exception of atomic $\mathrm{H}$ - not measured, the model results presented in Fig. 4 cannot directly be compared with experimental data. However, we can assess the reliability of the calculated radical densities indirectly by a comparison of those modeled ion densities which are produced predominantly by direct ionization from the corresponding radicals. The latter will be discussed in the following for $\mathrm{H}, \mathrm{N}, \mathrm{NH}$, and $\mathrm{NH}_{2}$. First we discuss here the correlation between radical densities and the resulting ion densities. As it was shown in a previous publication ${ }^{23}$ for a $\mathrm{H}_{2}-\mathrm{Ar}$ plasma at $1.0 \mathrm{~Pa}, \mathrm{H}^{+}$is mainly produced by electron-induced ionization from $\mathrm{H}$ (reaction 1.2: $\mathrm{e}^{-}+\mathrm{H} \rightarrow \mathrm{H}^{+}+2 \mathrm{e}^{-}$). This is also true for the $\mathrm{H}_{2}-\mathrm{N}_{2}$-Ar plasma where the fraction of reaction 1.2 on the total production rate is $R_{1.2} / R_{\text {tot }} \geq 67 \%$ for all considered $f_{\mathrm{N}_{2}}$. $\mathrm{H}^{+}$is mainly $\left(R_{w \mathrm{H}^{+}} / R_{t o t} \geq 53 \%\right)$ lost by recombination at the wall. $\mathrm{NH}^{+}$is primarily produced via reaction $1.17\left(\mathrm{e}^{-}+\mathrm{NH} \rightarrow \mathrm{NH}^{+}+2 \mathrm{e}^{-}\right)$. The contributions of reaction rate $R_{1.17} / R_{\text {tot }}$ to 
the total production rates at low and high $\mathrm{N}_{2}$ partial pressure fraction are $R_{1.17} / R_{\text {tot }}\left(f_{\mathrm{N}_{2}}=\right.$ $0.8 \%)=61 \%$ and $R_{1.17} / R_{\text {tot }}\left(f_{\mathrm{N}_{2}}=56 \%\right)=74 \%$, respectively. $\mathrm{NH}^{+}$is lost predominantly via reaction $2.28\left(\mathrm{NH}^{+}+\mathrm{H}_{2} \rightarrow \mathrm{NH}_{2}^{+}+\mathrm{H}\right)$. $\mathrm{N}^{+}$is not significantly produced from atomic nitrogen but from other species: from $\mathrm{N}_{2}$ via reaction $1.9\left(\mathrm{e}^{-}+\mathrm{N}_{2} \rightarrow \mathrm{N}^{+}+\mathrm{N}+2 \mathrm{e}^{-}\right)$, from $\mathrm{N}(D)$ via reaction $4.10\left(\mathrm{e}^{-}+\mathrm{N}(D) \rightarrow \mathrm{N}^{+}+2 \mathrm{e}^{-}\right)$, and from $\mathrm{NH}$ via reaction 1.18 $\left(\mathrm{e}^{-}+\mathrm{NH} \rightarrow \mathrm{N}^{+}+\mathrm{H}+2 \mathrm{e}^{-}\right) \cdot \mathrm{NH}_{2}^{+}$is almost exclusively $\left(R_{1.11} / R_{t o t} \geq 93 \%\right.$ for all considered $\left.f_{\mathrm{N}_{2}}\right)$ produced from $\mathrm{NH}_{3}$ via reaction $1.11\left(\mathrm{e}^{-}+\mathrm{NH}_{3} \rightarrow \mathrm{NH}_{2}^{+}+\mathrm{H}+2 \mathrm{e}^{-}\right)$. In conclusion, the densities of $\mathrm{H}$ and $\mathrm{NH}$ can be assessed by comparing with the corresponding ion densities. $\mathrm{NH}_{2}$ plays for the formation of $\mathrm{NH}_{2}^{+}$almost no role.

It is important to keep in mind, that two completely independent diagnostic methods were used to measure $n_{\mathrm{H}^{+}}$(Fig. 7) and $n_{\mathrm{H}}$ (Fig. 4), namely the plasma monitor (PM) and optical emission spectroscopy (OES), respectively. The calculated density of the $\mathrm{H}^{+}$ions deviates to higher values and agrees only within an averaged factor of 3.5 with the experimentally determined $\mathrm{H}^{+}$ion density measured with the PM. Furthermore, the calculated atomic $\mathrm{H}$ density agrees within an averaged factor of 1.6 with values measured with OES (see Sec. V D). However, mass spectrometer measurements at mass channel $1 \mathrm{amu} / \mathrm{e}$ are rather difficult and error-prone so that the measured $\mathrm{H}^{+}$density should be considered with great care. We, therefore, have a higher confidence in the calculated ion density than in the one measured with the PM. Nevertheless, the measured ion density is in an acceptable agreement with the calculated ion density and can at least be considered as indication that the order of magnitude of the calculated $\mathrm{H}$ atom density is also reasonable. In the case of the $\mathrm{H}$ atom density we have the additional OES data which are in good agreement with our model results. Finally, the calculated $\mathrm{NH}^{+}$ion density agrees satisfactorily with the measurement (see Fig. 8). The maximum deviation is a factor of 1.8. Since, as discussed above, $\mathrm{NH}^{+}$is mainly produced from $\mathrm{NH}$, we take this reasonable agreement as a confirmation that the $\mathrm{NH}$ density is calculated realistically.

\section{Variation of the Ar partial pressure}

In Sec. VI A we stated that in the $\mathrm{H}_{2}-\mathrm{N}_{2}$-Ar plasma with $1 \%$ Ar partial pressure fraction argon has only a small influence on the ion chemistry. To confirm this the influence of Ar is investigated by a $f_{\text {Ar }}$ variation between 0 and $56 \%$. To keep the total pressure constant, for a fixed $f_{\mathrm{N}_{2}} \approx 3 \%$ under otherwise identical plasma conditions $\left(p=1.5 \mathrm{~Pa}\right.$ and $\left.P_{r f}=200 \mathrm{~W}\right)$ the $\mathrm{H}_{2}$ partial pressure fraction was adjusted accordingly. The experimental and modeled results are shown in Figs. 10 and 11. It is worth mentioning that $n_{e}$ increases by one order of magnitude, but $n_{\mathrm{NH}_{3}}$ increases only slightly by a factor of 1.5 when increasing $f_{\mathrm{Ar}}$ from 0 to $56 \%$. $T_{e}$ decreases from $3.9 \mathrm{eV}\left(f_{\mathrm{Ar}}=0 \%\right)$ to $3.1 \mathrm{eV}\left(f_{\mathrm{Ar}}=56 \%\right)$. At $f_{\mathrm{Ar}}=1 \%$ and $f_{\mathrm{N}_{2}}=3 \% \mathrm{NH}_{3}^{+}$and $\mathrm{NH}_{4}^{+}$show the highest ion densities, followed by $\mathrm{N}_{2} \mathrm{H}^{+} \cdot n_{\mathrm{ArH}^{+}}$and $n_{\mathrm{Ar}^{+}}$ are one and two orders of magnitude below $n_{\mathrm{NH}_{3}^{+}}$, respectively. For an increase in Ar partial pressure fraction from 1 to $10 \%, n_{\mathrm{ArH}^{+}}$and $n_{\mathrm{Ar}^{+}}$increase by one order of magnitude while all other ion densities remain approximately constant. This confirms our statement from Sec. VIA. For larger partial pressure fraction the ion chemistry is influenced. In the range of $30 \%<f_{\mathrm{Ar}}<60 \% \mathrm{NH}_{3}^{+}$and $\mathrm{ArH}^{+}$are dominant. The agreement between calculated 


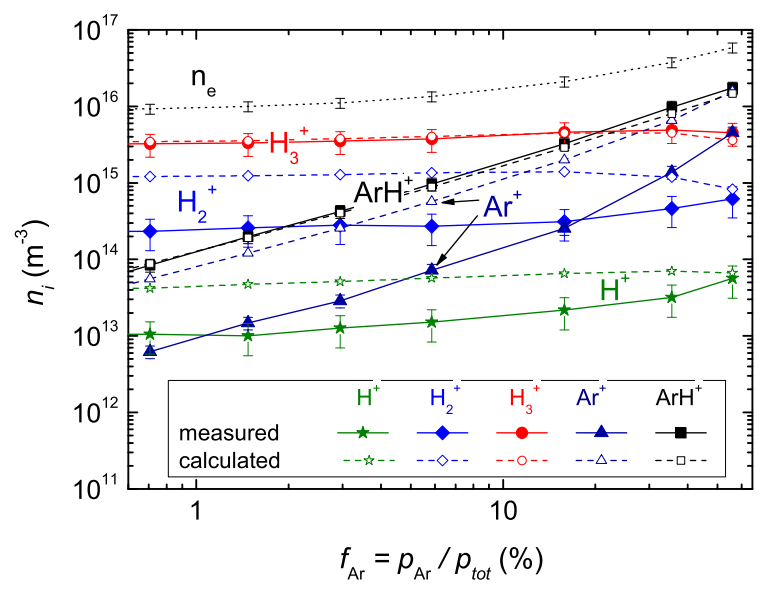

FIG. 10. Measured and calculated ion densities $n_{i}$ of $\mathrm{H}_{x}^{+}(x=1-3), \mathrm{Ar}^{+}$, and $\mathrm{ArH}^{+}$as well as $n_{e}$ as a function of $f_{\mathrm{Ar}}$.

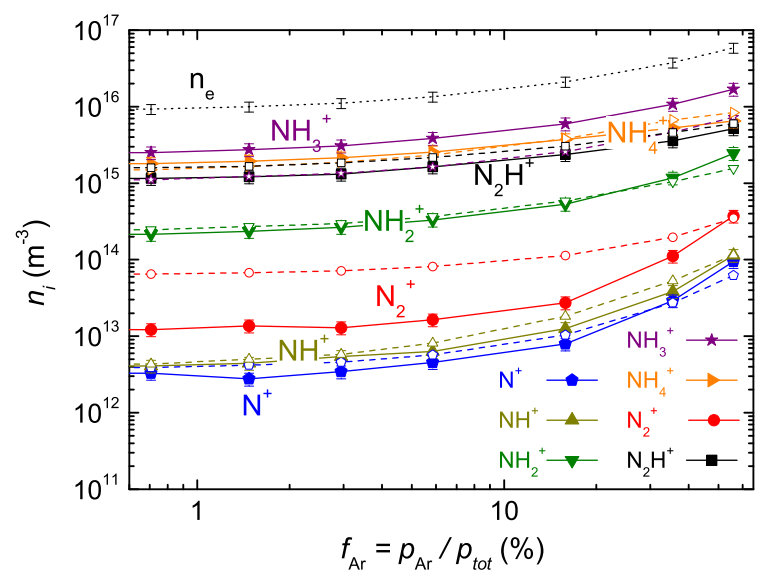

FIG. 11. Measured (solid symbols) and calculated (open symbols) ion densities $n_{i}$ of $\mathrm{NH}_{x}^{+}(x=$ $0-4), \mathrm{N}_{2}^{+}$, and $\mathrm{N}_{2} \mathrm{H}^{+}$as well as $n_{e}$ as a function of $f_{\mathrm{Ar}}$.

ion densities and experimental values is essentially the same as already discussed for the $\mathrm{N}_{2}$ variation. $\mathrm{ArH}^{+}$is formed primarily from $\mathrm{Ar}^{+}$via reaction $2.6\left(\mathrm{Ar}^{+}+\mathrm{H}_{2} \rightarrow \mathrm{ArH}^{+}+\mathrm{H}\right) . \mathrm{NH}_{3}^{+}$ is produced via reaction $1.10\left(\mathrm{e}^{-}+\mathrm{NH}_{3} \rightarrow \mathrm{NH}_{3}^{+}+2 \mathrm{e}^{-}\right)$and $2.39\left(\mathrm{Ar}^{+}+\mathrm{NH}_{3} \rightarrow \mathrm{NH}_{3}^{+}+\mathrm{Ar}\right)$. At $f_{\mathrm{Ar}}=56 \%$ the ion chemistry is significantly influenced by $\mathrm{ArH}^{+}$: While for lower $\mathrm{Ar}$ partial pressure fractions $\mathrm{NH}_{4}^{+}$and $\mathrm{N}_{2} \mathrm{H}^{+}$are produced by $\mathrm{H}_{3}^{+}$(see Fig. 9), for $f_{\mathrm{Ar}}=56 \%$ these ions are produced mainly from $\mathrm{ArH}^{+}$. 


\section{Comparison with a DC plasma}

Carrasco et al. ${ }^{3,28}$ studied $\mathrm{H}_{2}-\mathrm{N}_{2}$ low-pressure plasmas which are comparable to some extent to the here-investigated $\mathrm{H}_{2}-\mathrm{N}_{2}$-Ar plasma. They used a hollow cathode DC discharge in a cylindrical-shaped stainless steel plasma chamber with a chamber volume comparable to our setup. They measured the densities of neutral and ion species and compared their results with a rate equation model. In Ref. ${ }^{3}$ they investigated several pressures at a fixed $\mathrm{N}_{2}$ partial pressure fraction of $10 \%\left(P_{o f f}\right)$ and in Ref. ${ }^{28}$ a $f_{\mathrm{N}_{2}}$ variation at a constant pressure of $8 \mathrm{~Pa}$. They applied sheath voltages of 300-450 eV with corresponding sheath thicknesses in the range of $15-20 \mathrm{~mm}$. During $P_{\text {on }}$ the $\mathrm{N}_{2}$ partial pressure fraction measured with a quadrupole mass spectrometer was $f_{\mathrm{N}_{2}} \approx 7 \%$. It was independent of the investigated pressure within the experimental uncertainty. $f_{\mathrm{NH}_{3}}$ decreased from $5 \%$ at $0.8 \mathrm{~Pa}$ via $3 \%$ at $2 \mathrm{~Pa}$ to $2.5 \%$ at $8 \mathrm{~Pa}$. For comparison, the results in this work are $f_{\mathrm{NH}_{3}}=5.7 \%$ at $f_{\mathrm{N}_{2}}=7.9 \%$ and $p=1.5 \mathrm{~Pa}$. They measured an electron temperature and density of $T_{e}=(3.4 \pm 0.5) \mathrm{eV}$ and $n_{e}=(3.5 \pm 0.5) \times 10^{16} \mathrm{~m}^{-3}$, respectively, for $p=2 \mathrm{~Pa}$ and $f_{\mathrm{N}_{2}}=7 \%$. For comparison, in the present work at $p=1.5 \mathrm{~Pa}$ and $f_{\mathrm{N}_{2}}=7.9 \% T_{e}$ and $n_{e}$ are $(3.5 \pm 0.4) \mathrm{eV}$ and $(1.3 \pm 0.2) \times 10^{16} \mathrm{~m}^{-3}$, respectively. In view of the very different plasma generation type and the different plasma chamber geometries between the present work and Carrasco et al. we consider this a fairly good agreement. Thus, it is meaningful to compare the relative ion densities of the two considered studies with each other.

Carrasco et $a .^{3}$ calculated the densities of the ions and the radicals with a rate equation model comparable to the model applied in this work. Comparing the rate coefficients $K_{k}$ with $k=1.3,1.6,1.8-1.11,1.15-1.18$ for electron-induced collisions presented in Tab. II to data from Carrasco et al. ${ }^{3}$ in the $T_{e}$ range from 3 to $7 \mathrm{eV}$ we find an agreement within $30 \%$, whereas other $K_{k}$ from Tab. II deviate more than $30 \%^{54}$. The rate coefficients for the ion-molecule reactions agree between Carrasco et al. and the present work since both used values provided by Anicich ${ }^{66}$. Carrasco et al. use the ion wall loss rate coefficient $K_{w i}$ as fit parameter to fulfill the quasi-neutrality condition. In contrast, in the present study $K_{w i}$ is obtained by a sheath model, but $T_{e}$ is used as fit parameter to fulfill the quasi-neutrality condition.

Carrasco et al. ${ }^{3}$ measured the relative ion densities with a plasma monitor (plasma process monitor PPM 422) which is comparable to the instrument used in this work. For the relative ion concentration they integrated the measured ion energy distributions and multiplied the value by a mass transmission factor $T_{m d}$. They obtained experimentally a $T_{m d} \propto\left(M_{i}\right)^{-1 / 2}$ $\left(M_{i}\right.$ - ion mass) which is in agreement with the present study.

In a $\mathrm{H}_{2}-\mathrm{N}_{2}$ plasma investigated in Refs. ${ }^{3,28}$ two parameter variations were investigated: on the one hand, different pressures $(0.8,2 \text { and } 8 \mathrm{~Pa})^{3}$ at a fixed $\mathrm{N}_{2}$ partial pressure fraction of $f_{\mathrm{N}_{2}}=7 \%$ and, on the other hand, different $\mathrm{N}_{2}$ partial pressure fractions $\left(0<f_{\mathrm{N}_{2}}<10 \%\right)^{28}$ at a fixed pressure of $p=8 \mathrm{~Pa}$. At $f_{\mathrm{N}_{2}}=7 \%$ and $0.8 \mathrm{~Pa}$ they found that both model and experiment result in similar ion densities for $\mathrm{H}_{2}^{+}, \mathrm{H}_{3}^{+}, \mathrm{NH}_{3}^{+}, \mathrm{NH}_{4}^{+}$, and $\mathrm{N}_{2} \mathrm{H}^{+}$. For increasing pressure the $\mathrm{NH}_{4}^{+}$density increased and showed at $8 \mathrm{~Pa}$ the by far highest ion density ${ }^{3}$. Furthermore, Carrasco et al. reported that $\mathrm{NH}_{3}^{+}$is predominantly lost by recombination at the wall. This is also confirmed in the present work. In Ref. ${ }^{28}$ Carrasco et al. examined a 
$\mathrm{H}_{2}$ plasma at $8 \mathrm{~Pa}$ with small $\mathrm{N}_{2}$ admixture. They observed that for $0<f_{\mathrm{N}_{2}}<10 \%$ the secondary ions $\mathrm{H}_{3}^{+}, \mathrm{NH}_{4}^{+}$, and $\mathrm{N}_{2} \mathrm{H}^{+}$have the highest ion densities and that correspondingly the primary ions $\mathrm{H}_{2}^{+}$and $\mathrm{N}_{2}^{+}$contribute only a very small fraction to the total ion density. While in the $\mathrm{H}_{2}$ plasma with low $\mathrm{N}_{2}$ partial pressure fraction $\left(f_{\mathrm{N}_{2}}<2 \%\right) \mathrm{H}_{3}^{+}$is the dominant ion $^{28}, \mathrm{NH}_{4}^{+}$becomes dominant at increasing $f_{\mathrm{N}_{2}}\left(f_{\mathrm{N}_{2}}>4 \%\right)^{28}$. Also in the present work at $1.5 \mathrm{~Pa}$ and $f_{\mathrm{N}_{2}}<3 \%, \mathrm{H}_{3}^{+}$is the dominant ion species which is in accordance with Carrasco et al. ${ }^{28}$. In the present work at $f_{\mathrm{N}_{2}}>3 \%$ the ion densities of $\mathrm{NH}_{3}^{+}$and $\mathrm{NH}_{4}^{+}$are most abundant and have approximately the same values. It is important to note that a pressure of $8 \mathrm{~Pa}$ was used which causes a significant increase of $n_{\mathrm{NH}_{4}^{+}}$by charge exchange reactions compared to $n_{\mathrm{NH}_{3}^{+}}$.

Furthermore, it is interesting to note that Carrasco et al. ${ }^{28}$ also show modeling results for the time evolution of the ion species $\mathrm{H}_{3}^{+}, \mathrm{NH}_{3}^{+}, \mathrm{NH}_{4}^{+}$, and $\mathrm{N}_{2} \mathrm{H}^{+}$and the background gas densities after plasma ignition. For times $t$ lower than $0.1 \mathrm{~s}$ the $\mathrm{NH}_{3}$ density is of the order of the $\mathrm{N}_{2}$ density since $\mathrm{NH}_{3}$ is produced slowly by a number of reaction steps occurring at

the wall. $n_{\mathrm{H}_{3}^{+}}$shows a maximum at $t \approx 10^{-7} \mathrm{~s}$ (dominant ion), decreases further, and for $t \gtrsim 10^{-6} \mathrm{~s} \mathrm{H}_{3}^{+}$is replaced by $\mathrm{N}_{2} \mathrm{H}^{+}$as the dominant ion. Only for $t \gtrsim 3 \times 10^{-1} \mathrm{~s} \mathrm{NH}_{4}^{+}$ (produced by ion-molecule collisions with $\mathrm{NH}_{3}$, i.e., reactions 2.15, 2.35, and 2.38) becomes the dominant ion species because the production of ammonia occurring at the chamber wall $(t \approx 0.1 \mathrm{~s})$ is several orders of magnitudes slower than ionization processes $\left(t \approx 10^{-7} \mathrm{~s}\right)$. These results have clearly shown that $\mathrm{NH}_{4}^{+}$cannot be formed without $\mathrm{NH}_{3}$ being present which is in agreement with the result of the present rate equation model. In summary, the observations and discussions with respect to the ion densities and ion chemistry of $\mathrm{H}_{3}^{+}, \mathrm{NH}_{3}^{+}$, $\mathrm{NH}_{4}^{+}$, and $\mathrm{N}_{2} \mathrm{H}^{+}$between Carrasco et al. and the present work are essentially in agreement.

\section{SUMMARY}

Inductively coupled $\mathrm{H}_{2}-\mathrm{N}_{2}$-Ar plasmas were extensively studied at a pressure of $1.5 \mathrm{~Pa}$ and a $r f$ power of $200 \mathrm{~W}$. The $\mathrm{N}_{2}$ partial pressure fraction was increased from $f_{\mathrm{N}_{2}}=0$ to $56 \%$ by simultaneous reduction of the $\mathrm{H}_{2}$ partial pressure fraction. The Ar partial pressure fraction was constant at about $1 \%$. In the $\mathrm{H}_{2}-\mathrm{N}_{2}$ - $\mathrm{Ar}$ plasma the stable species $\mathrm{NH}_{3}$ is produced and contributes up to $12 \%$ to the background gas. In the studied plasma $\mathrm{NH}_{3}$ is almost exclusively produced on the surfaces of the chamber walls. The experimentally determined ion $\left(n_{i}\right)$ and radical $\left(n_{\text {rad }}\right)$ densities were compared to the results of a rate equation model.

To calculate the radical densities with the rate equation model it is necessary to know the corresponding wall loss times $t_{\text {wrad }}$ for the radical species. $t_{\text {wrad }}$ was determined experimentally by the decay of radical densities in the temporal afterglow of pulsed plasmas. With this the absolute densities of the radical species were calculated with the rate equation model.

The measurements with the plasma monitor show that $\mathrm{H}_{3}^{+}$is the dominant ion in the range of $0.0 \leq f_{\mathrm{N}_{2}}<3.4 \%$. For $3.4<f_{\mathrm{N}_{2}}<40 \% \mathrm{NH}_{3}^{+}$and $\mathrm{NH}_{4}^{+}$have the highest densities and their densities agree within the experimental uncertainty. For $f_{\mathrm{N}_{2}}=56 \% \mathrm{~N}_{2} \mathrm{H}^{+}$is the dominant ion and $\mathrm{NH}_{3}^{+}$and $\mathrm{NH}_{4}^{+}$have a slightly lower density. These four most abundant ion species contribute more than $90 \%$ to the total ion density $n_{i, t o t}$ for all considered $f_{\mathrm{N}_{2}}$. Ion species with densities in the range between 0.5 and $10 \%$ of $n_{i, t o t}$ are $\mathrm{H}_{2}^{+}, \mathrm{ArH}^{+}$, and 
$\mathrm{NH}_{2}^{+}$. Ion species with densities less than $0.5 \%$ of $n_{i, t o t}$ are $\mathrm{H}^{+}, \mathrm{Ar}^{+}, \mathrm{N}^{+}$, and $\mathrm{NH}^{+}$.

The applied rate equation model describes the measured ion densities of the $\mathrm{H}_{2}-\mathrm{N}_{2}-\mathrm{Ar}$ plasmas reasonably well. The main features, i.e., the qualitative abundance of the ion species and the dependence of the ion density on the $\mathrm{N}_{2}$ partial pressure fraction as well as the electron temperature, are well reproduced by the model. Nevertheless, some quantitative deviations between model and experiment remain. The main discrepancy is that the modeled densities of the primary ions $\mathrm{H}_{2}^{+}, \mathrm{N}_{2}^{+}$, and $\mathrm{Ar}^{+}$are clearly higher than the measured values.

Overall, a comprehensive investigation of inductively coupled $\mathrm{H}_{2}-\mathrm{N}_{2}$-Ar plasmas was carried out which results in the experimental determination of absolute ion and radical densities. Furthermore, the densities were calculated using a zero-dimensional model, which adequately describes the main features of the measured densities. The model allows to identify the most important plasma-chemical reactions in the investigated $\mathrm{H}_{2}-\mathrm{N}_{2}$-Ar plasma.

\section{ACKNOWLEDGMENTS}

We gratefully acknowledge help from T. Dürbeck and W. Hohlenburger for technical assistance.

\section{REFERENCES}

${ }^{1}$ S. Xu, S. Y. Huang, I. Levchenko, H. P. Zhou, D. Y. Wei, S. Q. Xiao, L. X. Xu, W. S. Yan, and K. Ostrikov, "Highly efficient silicon nanoarray solar cells by a single-step plasmabased process," Advanced Energy Materials 1, 373-376 (2011).

${ }^{2}$ K. Ostrikov, U. Cvelbar, and A. B. Murphy, "Plasma nanoscience: setting directions, tackling grand challenges," Journal of Physics D: Applied Physics 44, 174001 (2011).

${ }^{3}$ E. Carrasco, M. Jimenez-Redondo, I. Tanarro, and V. J. Herrero, "Neutral and ion chemistry in low pressure dc plasmas of $\mathrm{H}_{2} / \mathrm{N}_{2}$ mixtures: routes for the efficient production of $\mathrm{NH}_{3}$ and $\mathrm{NH}_{4}^{+}$," Phys. Chem. Chem. Phys. 13, 19561-19572 (2011).

${ }^{4}$ T.-P. Ma, "Making silicon nitride film a viable gate dielectric," IEEE Transactions on Electron Devices 45, 680-690 (1998).

${ }^{5}$ A. G. Aberle, "Overview on SiN surface passivation of crystalline silicon solar cells," Solar Energy Materials and Solar Cells 65, 239 - 248 (2001), PVSEC 11 Part I.

${ }^{6}$ H. Nagai, S. Takashima, M. Hiramatsu, M. Hori, and T. Goto, "Behavior of atomic radicals and their effects on organic low dielectric constant film etching in high density $\mathrm{N}_{2} / \mathrm{H}_{2}$ and $\mathrm{N}_{2} / \mathrm{NH}_{3}$ plasmas," J. Appl. Phys. 91, 2615-2621 (2002).

${ }^{7}$ C. S. Moon, K. Takeda, S. Takashima, M. Sekine, Y. Setsuhara, M. Shiratani, and M. Hori, "Surface loss probabilities of $\mathrm{H}$ and $\mathrm{N}$ radicals on different materials in afterglow plasmas employing $\mathrm{H}_{2}$ and $\mathrm{N}_{2}$ mixture gases," Journal of Applied Physics 107, 103310 (2010).

${ }^{8}$ J. H. van Helden, P. J. van den Oever, W. M. M. Kessels, M. C. M. van de Sanden, D. C. Schram, and R. Engeln, "Production mechanisms of $\mathrm{NH}$ and $\mathrm{NH}_{2}$ radicals in $\mathrm{N}_{2}-\mathrm{H}_{2}$ plasmas," The Journal of Physical Chemistry A 111, 11460-11472 (2007), pMID: 17929903, http://pubs.acs.org/doi/pdf/10.1021/jp0727650. 
${ }^{9}$ A. Ricard, B. F. Gordiets, M. J. Pinheiro, C. M. Ferreira, G. Baravian, J. Amorim, S. Bockel, and H. Michel, "Diagnostic and modeling of $\mathrm{N}_{2}-\mathrm{H}_{2}$ discharges for iron nitriding," The European Physical Journal - Applied Physics 4, 87-93 (1998).

${ }^{10}$ H. Kim, "Atomic layer deposition of metal and nitride thin films: Current research efforts and applications for semiconductor device processing," J. Vac. Sci. Technol. B 21, 22312261 (2003).

${ }^{11}$ K. V. Laer, S. Tinck, V. Samara, J. F. de Marneffe, and A. Bogaerts, "Etching of low-k materials for microelectronics applications by means of a $\mathrm{N}_{2} / \mathrm{H}_{2}$ plasma: modeling and experimental investigation," Plasma Sources Sci. Technol. 22, 025011 (2013).

${ }^{12}$ E. N. Eremin, Russ. J. Phys. Chem. 49, 1112 (1975).

${ }^{13}$ P. Vankan, T. Rutten, S. Mazouffre, D. C. Schram, and R. Engeln, "Absolute density measurements of ammonia produced via plasma-activated catalysis," Applied Physics Letters 81, 418-420 (2002).

${ }^{14}$ D. Neuwirth, V. Rohde, T. Schwarz-Selinger, and A. U. G. Team, "Formation of ammonia during nitrogen-seeded discharges at ASDEX Upgrade," Plasma Physics and Controlled Fusion 54, 085008 (2012).

${ }^{15}$ M. Oberkofler, D. Douai, S. Brezinsek, J. Coenen, T. Dittmar, A. Drenik, S. Romanelli, E. Joffrin, K. McCormick, M. Brix, G. Calabro, M. Clever, C. Giroud, U. Kruezi, K. Lawson, C. Linsmeier, A. M. Rojo, A. Meigs, S. Marsen, R. Neu, M. Reinelt, B. Sieglin, G. Sips, M. Stamp, and F. Tabares, "First nitrogen-seeding experiments in JET with the ITER-like wall," Journal of Nuclear Materials 438, Supplement, S258 - S261 (2013), proceedings of the 20th International Conference on Plasma-Surface Interactions in Controlled Fusion Devices.

${ }^{16}$ A. Kallenbach, R. Dux, J. C. Fuchs, R. Fischer, B. Geiger, L. Giannone, A. Herrmann, T. Lunt, V. Mertens, R. McDermott, R. Neu, T. Puetterich, S. Rathgeber, V. Rohde, K. Schmid, J. Schweinzer, W. Treutterer, and A. U. G. Team, "Divertor power load feedback with nitrogen seeding in ASDEX Upgrade," Plasma Physics and Controlled Fusion 52, 055002 (2010).

${ }^{17}$ A. Kallenbach, M. Balden, R. Dux, T. Eich, C. Giroud, A. Huber, G. Maddison, M. Mayer, K. McCormick, R. Neu, T. Petrie, T. Ptterich, J. Rapp, M. Reinke, K. Schmid, J. Schweinzer, and S. Wolfe, "Plasma surface interactions in impurity seeded plasmas," Journal of Nuclear Materials 415, S19 - S26 (2011), proceedings of the 19th International Conference on Plasma-Surface Interactions in Controlled Fusion.

${ }^{18}$ A. Kallenbach, M. Bernert, T. Eich, J. Fuchs, L. Giannone, A. Herrmann, J. Schweinzer, W. Treutterer, and A. U. G. Team, "Optimized tokamak power exhaust with double radiative feedback in ASDEX Upgrade," Nuclear Fusion 52, 122003 (2012).

${ }^{19}$ G. Maddison, C. Giroud, B. Alper, G. Arnoux, I. Balboa, M. N. A. Beurskens, A. Boboc, S. Brezinsek, M. Brix, M. Clever, R. Coelho, J. W. Coenen, I. Coffey, P. C. da Silva Aresta Belo, S. Devaux, P. Devynck, T. Eich, R. C. Felton, J. Flanagan, L. Frassinetti, L. Garzotti, M. Groth, S. Jachmich, A. Järvinen, E. Joffrin, M. A. H. Kempenaars, U. Kruezi, K. D. Lawson, M. Lehnen, M. J. Leyland, Y. Liu, P. Lomas, C. G. Lowry, S. Marsen, G. F. Matthews, G. K. McCormick, A. G. Meigs, A. W. Morris, R. Neu, I. Nunes, M. Oberkofler, F. G. Rimini, S. Saarelma, B. Sieglin, A. C. C. Sips, A. Sirinelli, 
M. F. Stamp, G. J. van Rooij, D. J. Ward, M. Wischmeier, and J. E. T. E. F. D. A. Contributors, "Contrasting H-mode behaviour with deuterium fuelling and nitrogen seeding in the all-carbon and metallic versions of JET," Nuclear Fusion 54, 073016 (2014).

${ }^{20}$ J. L. Jauberteau, I. Jauberteau, and J. Aubreton, " $\mathrm{NH}_{3}$ and $\mathrm{NH}_{x<3}$ radicals synthesis downstream a microwave discharge sustained in an $\mathrm{Ar}-\mathrm{N}_{2}-\mathrm{H}_{2}$ gas mixture. Study of surface reactive processes and determination of rate constants," Journal of Physics D: Applied Physics 35, 665 (2002).

${ }^{21}$ I. Jauberteau, J. L. Jauberteau, M. N. Séméria, A. Larré, J. Piaguet, and J. Aubreton, "Plasma nitriding of thin molybdenum layers at low temperature," Surface and Coatings Technology 116 - 119, 222 - 228 (1999).

${ }^{22}$ M. Sode, T. Schwarz-Selinger, and W. Jacob, "Quantitative determination of massresolved ion densities in $\mathrm{H}_{2}$-Ar inductively coupled radio frequency plasmas," Journal of Applied Physics 113, 093304 (2013).

${ }^{23}$ M. Sode, T. Schwarz-Selinger, and W. Jacob, "Ion chemistry in $\mathrm{H}_{2}$-Ar low temperature plasmas," Journal of Applied Physics 114, 063302 (2013).

${ }^{24}$ N. Fox-Lyon and G. S. Oehrlein, "Isotope effects on plasma species of $\mathrm{Ar} / \mathrm{H}_{2} / \mathrm{D}_{2}$ plasmas," J. Vac. Sci. Technol. B 32, 041206 (2014).

${ }^{25}$ M. Jimenez-Redondo, M. Cueto, J. L. Domenech, I. Tanarro, and V. J. Herrero, "Ion kinetics in $\mathrm{Ar} / \mathrm{H}_{2}$ cold plasmas: the relevance of $\mathrm{ArH}^{+}$," RSC Adv. 4, 62030-62041 (2014).

${ }^{26}$ R. A. Arakoni, A. N. Bhoj, and M. J. Kushner, " $\mathrm{H}_{2}$ generation in Ar/ $\mathrm{NH}_{3}$ microdischarges," Journal of Physics D: Applied Physics 40, 2476 (2007).

${ }^{27}$ E. Carrasco, V. J. Herrero, and I. Tanarro, "Time-resolved diagnostics and kinetic modelling of the ignition transient of a $\mathrm{H}_{2}+0.1 \mathrm{~N}_{2}$ square wave modulated hollow cathode discharge," Journal of Physics D: Applied Physics 45, 305201 (2012).

${ }^{28}$ E. Carrasco, I. Tanarro, V. J. Herrero, and J. Cernicharo, "Proton transfer chains in cold plasmas of $\mathrm{H}_{2}$ with small amounts of $\mathrm{N}_{2}$. the prevalence of $\mathrm{NH}_{4}^{+}$," Phys. Chem. Chem. Phys. 15, 1699-1706 (2013).

${ }^{29} \mathrm{~S}$. Jang and W. Lee, "Pressure and input power dependence of $\mathrm{Ar} / \mathrm{N}_{2} \mathrm{H}_{2}$ inductively coupled plasma systems," J. Vac. Sci. Technol. A 19, 2335 (2001).

${ }^{30}$ J. H. van Helden, W. Wagemans, G. Yagci, R. A. B. Zijlmans, D. C. Schram, R. Engeln, G. Lombardi, G. D. Stancu, and J. Röpcke, "Detailed study of the plasma-activated catalytic generation of ammonia in $\mathrm{N}_{2}-\mathrm{H}_{2}$ plasmas," Journal of Applied Physics 101, 043305 (2007).

${ }^{31}$ S. J. Kang and V. M. Donnelly, "Optical absorption and emission spectroscopy studies of ammonia-containing plasmas," Plasma Sources Sci. Technol. 16, 265 (2007).

${ }^{32}$ S. Chen, H. Kondo, K. Ishikawa, K. Takeda, M. Sekine, H. Kano, S. Den, and M. Hori, "Behaviors of absolute densities of $\mathrm{N}, \mathrm{H}$, and $\mathrm{NH}_{3}$ at remote region of high-density radical source employing $\mathrm{N}_{2}-\mathrm{H}_{2}$ mixture plasmas," Japanese Journal of Applied Physics 50, 01AE03 (2011).

${ }^{33}$ I. Burlacov, K. Börner, H.-J. Spies, H. Biermann, D. Lopatik, H. Zimmermann, and J. Röpcke, "In-situ monitoring of plasma enhanced nitriding processes using infrared absorption and mass spectroscopy," Surface and Coatings Technology 206, 3955 - 3960 (2012). 
${ }^{34}$ C. S. Moon, K. Takeda, S. Takashima, M. Sekine, Y. Setsuhara, M. Shiratani, and M. Hori, "High performance of compact radical monitoring probe in $\mathrm{H}_{2} / \mathrm{N}_{2}$ mixture plasma," J. Vac. Sci. Technol. B: Microelectronics and Nanometer Structures 28, L17-L20 (2010).

${ }^{35} \mathrm{~S}$. Touimi, J. L. Jauberteau, I. Jauberteau, and J. Aubreton, "Plasma chemistry and diagnostic in an Ar- $\mathrm{N}_{2}-\mathrm{H}_{2}$ microwave expanding plasma used for nitriding treatments," Journal of Physics D: Applied Physics 43, 205203 (2010).

${ }^{36}$ S. Peter, R. Pintaske, G. Hecht, and F. Richter, "Determination of mass and energy distribution of ions in glow discharges," Surface and Coatings Technology 59, 97 - 100 (1993).

${ }^{37}$ B. Gordiets, C. M. Ferreira, M. J. Pinheiro, and A. Ricard, "Self-consistent kinetic model of low-pressure $\mathrm{N}_{2}-\mathrm{H}_{2}$ flowing discharges: I. Volume processes," Plasma Sources Sci. Technol. 7, 363 (1998).

${ }^{38}$ B. Gordiets, C. M. Ferreira, M. J. Pinheiro, and A. Ricard, "Self-consistent kinetic model of low-pressure $\mathrm{N}_{2}-\mathrm{H}_{2}$ flowing discharges: II. Surface processes and densities of $\mathrm{N}, \mathrm{H}, \mathrm{NH}_{3}$ species," Plasma Sources Sci. Technol. 7, 379 (1998).

${ }^{39}$ E. Tatarova, F. M. Dias, B. Gordiets, and C. M. Ferreira, "Molecular dissociation in $\mathrm{N}_{2}-\mathrm{H}_{2}$ microwave discharges," Plasma Sources Sci. Technol. 14, 19 (2005).

${ }^{40} \mathrm{~A}$. Garscadden and R. Nagpal, "Non-equilibrium electronic and vibrational kinetics in $\mathrm{H}_{2}-\mathrm{N}_{2}$ and $\mathrm{H}_{2}$ discharges," Plasma Sources Sci. Technol. 4, 268 (1995).

${ }^{41} \mathrm{~V}$. A. Kadetov, Diagnostics and modeling of an inductively coupled radio frequency discharge in hydrogen, PhD thesis, Ruhr Universität Bochum (2004).

${ }^{42} \mathrm{~W}$. Walcher, "Über eine Ionenequelle für massenspektroskopische Isotopentrennung," Zeitschrift für Physik 122, 62-85 (1944).

${ }^{43}$ M. Sode, T. Schwarz-Selinger, W. Jacob, and H. Kersten, "Wall loss of atomic nitrogen determined by ionization threshold mass spectrometry," Journal of Applied Physics 116, 193302 (2014).

${ }^{44}$ M. Sode, T. Schwarz-Selinger, W. Jacob, and H. Kersten, "Surface loss probability of atomic hydrogen for different electrode cover materials investigated in $\mathrm{H}_{2}$-Ar low-pressure plasmas," Journal of Applied Physics 116, 013302 (2014).

${ }^{45}$ S. V. Dudin, A. P. Jatskov, and V. I. Farenik, Tekhnologiya i Konstruirovaniye v Elektronnoi Apparature 3, 43 (2002).

${ }^{46}$ P. McNeely, S. Dudin, S. Christ-Koch, and U. Fantz, "A Langmuir probe system for high power RF-driven negative ion sources on high potential," Plasma Sources Sci. Technol. 18, 014011 (2009).

${ }^{47}$ H. Singh, J. W. Coburn, and D. B. Graves, "Appearance potential mass spectrometry: Discrimination of dissociative ionization products," J. Vac. Sci. Technol. A 18, 299 (2000).

${ }^{48}$ S. Matsuda, H. Shimosato, M. Yumoto, and T. Sakai, "Detection of nitrogen metastable molecules by using the threshold ionization mass spectrometry," Electrical Engineering in Japan 147, 17-24 (2004).

${ }^{49}$ H. Singh, J. W. Coburn, and D. B. Graves, "Recombination coefficients of O and N radicals on stainless steel," Journal of Applied Physics 88, 3748-3755 (2000).

${ }^{50} \mathrm{P}$. Kae-Nune, J. Perrin, J. Jolly, and J. Guillon, "Surface recombination probabilities of $\mathrm{H}$ on stainless steel, a-Si:H and oxidized silicon determined by threshold ionization mass 
spectrometry in $\mathrm{H}_{2}$ RF discharges," Surface Science Letters 360, L495 (1996).

${ }^{51}$ M. Bauer, T. Schwarz-Selinger, W. Jacob, and A. v. Keudell, "Growth precursor for a$\mathrm{C}: \mathrm{H}$ film deposition in pulsed inductively coupled methane plasmascontrol of the plasma chemistry of a pulsed inductively coupled methane plasma," J. Appl. Phys. 98, 073302 (2005).

${ }^{52}$ T. Schwarz-Selinger, V. Dose, W. Jacob, and A. von Keudell, "Quantification of a radical beam source for methyl radicals," J. Vac. Sci. Technol. A 19, 101 (2001).

${ }^{53}$ S. Agarwal, B. Hoex, M. C. M. van de Sanden, D. Maroudas, and E. S. Aydil, "Absolute densities of $\mathrm{N}$ and excited $\mathrm{N}_{2}$ in a $\mathrm{N}_{2}$ plasma," Applied Physics Letters 83, 4918-4920 (2003).

${ }^{54} \mathrm{M}$. Sode, Quantitative Beschreibung von Wasserstoff-Stickstoff-Argon-Mischplasmen, $\mathrm{PhD}$ thesis (in German), Universität Kiel (2013), http://d-nb.info/1048558398.

${ }^{55}$ A. Sandu and R. Sanders, KPP - The kinetic preprocessor, Version 2.2.1 (2006), http://people.cs.vt.edu/ asandu/Software/Kpp/.

${ }^{56}$ V. Damian, A. Sandu, M. Damian, F. Potra, and G. R. Carmichael, "The kinetic preprocessor KPP-a software environment for solving chemical kinetics," Computers and Chemical Engineering 26, 1567-1579 (2002).

${ }^{57}$ T. Kimura and H. Kasugai, "Properties of inductively coupled rf $\mathrm{Ar} / \mathrm{H}_{2}$ plasmas: Experiment and global model," J. Appl. Phys. 107, 083308 (2010).

${ }^{58}$ J.-S. Yoon, M.-Y. Song, J.-M. Han, S. H. Hwang, W.-S. Chang, B. Lee, and Y. Itikawa, "Cross sections for electron collisions with hydrogen molecules," J. Phys. Chem. Ref. Data 37, 913-931 (2008).

${ }^{59}$ M. B. Shah, D. S. Elliott, and H. B. Gilbody, "Pulsed crossed-beam study of the ionisation of atomic hydrogen by electron impact," Journal of Physics B: Atomic and Molecular Physics 20, 3501-3514 (1987).

${ }^{60}$ R. C. Wetzel, F. A. Baiocchi, T. R. Hayes, and R. S. Freund, "Absolute cross sections for electron-impact ionization of the rare-gas atoms by the fast-neutral-beam method," Phys. Rev. A 35, 559-577 (1987).

${ }^{61}$ Y. Itikawa, "Cross sections for electron collisions with nitrogen molecules," Journal of Physical and Chemical Reference Data 35, 31-53 (2006).

${ }^{62}$ Y.-K. Kim and J.-P. Desclaux, "Ionization of carbon, nitrogen, and oxygen by electron impact," Phys. Rev. A 66, 012708 (2002).

${ }^{63}$ V. Tarnovsky, H. Deutsch, and K. Becker, "Cross-sections for the electron impact ionization of $\mathrm{ND}_{x}(\mathrm{x}=1-3)$," International Journal of Mass Spectrometry and Ion Processes 167/168, 69 - 78 (1997).

${ }^{64}$ T. D. Märk, F. Egger, and M. Cheret, "Ionization of ammonia and deuterated ammonia by electron impact from threshold up to $180 \mathrm{eV}$," The Journal of Chemical Physics 67, 3795-3802 (1977).

${ }^{65}$ M. Yousfi and M. D. Benabdessadok, "Boltzmann equation analysis of electron-molecule collision cross sections in water vapor and ammonia," Journal of Applied Physics 80, 6619-6630 (1996).

${ }^{66} \mathrm{~V}$. K. Anicich, "Evaluated bimolecular ion-molecule gas phase kinetics of positive ions for use in modelling planetary atmospheres, cometary comae, and interstellar clouds," J. 
Phys. Chem. Ref. Data 22, 1469-1569 (1993).

${ }^{67} \mathrm{~K}$. Tao, D. Mao, and J. Hopwood, "Ionized physical vapor deposition of titanium nitride: A global plasma model," Journal of Applied Physics 91, 4040-4048 (2002).

${ }^{68}$ M. A. Lieberman and A. J. Lichtenberg, Principles of plasma discharges and materials processing (John Wiley and Sons, Inc., Hoboken, New Jersey, 2005).

${ }^{69}$ V. A. Godyak, Soviet Radio Frequency Discharge Research, Delphic Associates, Falls Church, VA (1986).

${ }^{70}$ A. Bogaerts and R. Gijbels, "Hybrid Monte Carlo-fluid modeling network for an argon/hydrogen direct current glow discharge," Spectrochimica Acta Part B 57, 1071-1099 (2002).

${ }^{71}$ A. V. Phelps, "Cross sections and swarm coefficients for nitrogen ions and neutrals in $\mathrm{N}_{2}$ and argon ions and neutrals in Ar for energies from $0.1 \mathrm{eV}$ to $10 \mathrm{keV}$," J. Phys. Chem. Ref. Data 20, 557 (1991).

${ }^{72}$ V. Voitsenya, S. Masuzaki, O. Motojima, and A. Sagara, "Impact of $\mathrm{N}_{2}-\mathrm{H}_{2}$ mixture plasma on carbon-containing film," Problems of Atomic Science and Technology 2006, 141-143 (2006), number 6.

${ }^{73} \mathrm{~V}$. Voitsenya, S. Masuzaki, O. Motojima, and A. Sagara, "Impact of $\mathrm{N}_{2}-\mathrm{H}_{2}$ mixture plasma on carbon-containing film," (2006), unpublished.

${ }^{74} \mathrm{M}$. T. Bowers and D. D. Elleman, "Kinetic analysis of the concurrent ion-molecule reactions in mixtures of argon and nitrogen with $\mathrm{H}_{2}, \mathrm{D}_{2}$, and $\mathrm{HD}$ utilizing ion-ejection-ioncyclotron-resonance techniques," The Journal of Chemical Physics 51, 4606-4617 (1969).

${ }^{75}$ A. T. Hjartarson, E. G. Thorsteinsson, and J. T. Gudmundsson, "Low pressure hydrogen discharges diluted with argon explored using a global model," Plasma Sources Sci. Technol. 19, 065008 (2010).

${ }^{76}$ T. Kimura and H. Kasugai, "Experiments and global model of inductively coupled rf Ar/ $\mathrm{N}_{2}$ discharges," Journal of Applied Physics 108, 033305 (2010).

${ }^{77}$ E. G. Thorsteinsson and J. T. Gudmundsson, "A global (volume averaged) model of a nitrogen discharge: I. steady state," Plasma Sources Sci. Technol. 18, 045001 (2009).

${ }^{78}$ M. Gerl, Modellierung von Teilchendichten in Stickstoff-Niedertemperaturplasmen, Bachelor thesis (in German), Technische Universität München (2011).

${ }^{79} \mathrm{P}$. J. Chantry, "A simple formula for diffusion calculations involving wall reflection and low density," J. Appl. Phys. 62, 1141-1148 (1987).

${ }^{80}$ S. Takashima, M. Hori, T. Goto, A. Kono, and K. Yoneda, "Absolute concentration and loss kinetics of hydrogen atom in methane and hydrogen plasmas," Journal of Applied Physics 90, 5497-5503 (2001).

${ }^{81}$ J. Jolly and J.-P. Booth, "Atomic hydrogen densities in capacitively coupled very highfrequency plasmas in $\mathrm{H}_{2}$ : Effect of excitation frequency," J. Appl. Phys. 97, 103305 (6pp) (2005).

${ }^{82}$ A. Rousseau, G. Cartry, and X. Duten, "Surface recombination of hydrogen atoms studied by a pulsed plasma excitation technique," Journal of Applied Physics 89, 2074-2078 (2001).

${ }^{83} \mathrm{~K}$. Kutasi and J. Loureiro, "Role of the wall reactor material on the species density distributions in an $\mathrm{N}_{2} \mathrm{O}_{2}$ post-discharge for plasma sterilization," J. Phys. D. 40, 5612 (2007). ${ }^{84}$ U. Cvelbar, M. Mozetič, I. Poberaj, D. Babič, and A. Ricard, "Characterization of hy- 
drogen plasma with a fiber optics catalytic probe," Thin Solid Films 475, 12-16 (2005).

${ }^{85}$ F. Gaboriau, U. Cvelbar, M. Mozetič, A. Erradi, and B. Rouffet, "Comparison of TALIF and catalytic probes for the determination of nitrogen atom density in a nitrogen plasma afterglow," Journal of Physics D: Applied Physics 42, 055204 (2009).

${ }^{86}$ A. D. Tserepi and T. A. Miller, "Two-photon absorption laser-induced fluorescence of $\mathrm{H}$ atoms: A probe for heterogeneous processes in hydrogen plasmas," Journal of Applied Physics 75, 7231-7236 (1994).

${ }^{87}$ S. F. Adams and T. A. Miller, "Surface and volume loss of atomic nitrogen in a parallel plate rf discharge reactor," Plasma Sources Sci. Technol. 9, 248 (2000).

${ }^{88}$ M. Osiac, T. Schwarz-Selinger, D. O'Connell, B. Heil, Z. L. Petrovic, M. M. Turner, T. Gans, and U. Czarnetzki, "Plasma boundary sheath in the afterglow of a pulsed inductively coupled RF plasma," Plasma Sources Sci. Technol. 16, 355-363 (2007).

${ }^{89} \mathrm{~W}$. Poschenrieder, Private communication, 2012.

${ }^{90}$ N. G. Adams, D. Smith, and J. F. Paulson, "An experimental survey of the reactions of $\mathrm{NH}_{n}^{+}$ions $(n=0$ to 4$)$ with several diatomic and polyatomic molecules at $300 \mathrm{~K}$," The Journal of Chemical Physics 72, 288-297 (1980).

${ }^{91}$ E. P. L. Hunter and S. G. Lias, "Evaluated gas phase basicities and proton affinities of molecules: An update," Journal of Physical and Chemical Reference Data 27, 413 (1998). 